\title{
Pain is so close to pleasure: the same dopamine neurons can mediate approach and avoidance in Drosophila
}

\author{
Christian Rohrsen ${ }^{1}$, Aida Kumpf ${ }^{1}$, Kader Semiz ${ }^{1}$, Ferruh Aydin ${ }^{1}$, \\ Benjamin deBivort ${ }^{2}$, Björn Brembs ${ }^{1 *}$ \\ ${ }^{1}$ Universität Regensburg, Institut für Zoologie - Neurogenetik \\ ${ }^{2}$ Harvard University, Center for Brain Science and Department of Organismic and Evolutionary \\ Biology
}

*bjoern@brembs.net

\section{Abstract}

In mammals, dopamine is considered a central neuromodulator involved in all kinds of rewarding experiences ('common currency' hypothesis). In insects, the role of dopaminergic neurons in aversive stimuli was discovered before dopaminergic neurons were found to also be involved in processing appetitive stimuli. Here, we screened about 50 transgenic Drosophila lines, representing different subpopulations of dopaminergic neurons for their ability to sustain approach or avoidance behavior, when activated optogenetically in four different operant self-stimulation paradigms. None of the lines sustain consistent behavioral valence in all experiments. Individual lines sustain approach in one experiment and avoidance in another. One line mediated strong avoidance early in the experiment and weak approach in later stages. The evidence presented here appears to contradict a 'common currency' dopamine function in flies. Instead, different dopaminergic neurons convey valence in a contextdependent and flexible manner, reflecting the genetic heterogeneity of the dopaminergic neuronal population. 


\section{Introduction}

Motivation, attention and value are central for adaptive behavioral choice and, hence, evolutionary fitness. The literature on dopamine function suggests a substantial and evolutionary conserved role of dopamine neurons (DANs) in all three processes. The function of DANs in valuation, in terms of reward and punishment, has been especially prominent, in particular with regard to clinical aspects of tolerance and addiction to drugs of abuse. In vertebrates, midbrain DANs have been reported to encode reward prediction errors in classical conditioning experiments (Bayer and Glimcher, 2005; Schultz, 2019, 2017, 2016; Schultz et al., 1993) and if these neurons are driven optogenetically in an operant place learning task, they can substitute for reward (Kremer et al., 2020). Drugs of abuse primarily target this dopaminergic system and promote debilitating loss of behavioral control once an addiction has been established.

Also in flies, dopamine neurons have been reported to be involved in valuation processes in classical conditioning experiments. Early on, Dopa decarboxylase, an enzyme required for the synthesis of dopamine, was shown to be involved in olfactory classical conditioning (Tempel et al., 1984). Silencing of DANs blocks acquisition of 
aversive classical memory, but leaves appetitive memory intact (Schwaerzel et al., 2003). Dopamine receptors are necessary for olfactory classical conditioning (Kim et al., 2007; Qin et al., 2012). Optogenetic activation of DANs paired with an olfactory conditioned stimulus (CS) is able to replace sugar as the unconditioned stimulus (US) (Aso et al., 2014, 2012, 2010; Liu et al., 2012). In an operant olfactory conditioning paradigm in flies, optogenetic activation of TH-Gal4 DANs served as punishment and was able to induce an olfactory preference (Claridge-Chang et al., 2009). Also in Drosophila larvae, DANs appear to serve analogous functions (Lesar et al., 2021; Rohwedder et al., 2016; Schleyer et al., 2020, 2013). DANs and octopaminergic neurons also appear to be involved in value-based decision-making in flies (Gorostiza et al., 2016), adding additional evidence for the valuation-related function of DANs.

From these results and more like these, a prominent, general role of DANs in value processing was derived and DAN activity interpreted as participating in the computation of a "common currency" of value into which information from all sensory modalities are converted (Berridge and Kringelbach, 2015; Grabenhorst and Rolls, 2011; Kobayashi and Hsu, 2019; Lak et al., 2014; Landreth and Bickle, 2008; Levy and Glimcher, 2012; Matsumoto et al., 2016; Schultz et al., 2015). 
It is thought that the same DANs encode, e.g., rewards from food, drink, sex or money, while separate sets encode aversive stimuli like heat, electric shock or loss.

Taken together, the current picture of DAN function in value computations entails that every animal possesses sets of DANs that encode value on an appetitive/aversive scale such that they mediate approach and avoidance behaviors, respectively. In this conceptual framework, animals should seek to activate the 'appetitive' DANs and seek to silence the 'aversive' DANs, irrespective of how the animal is allowed to do that. In the fruit fly Drosophila, we can test this hypothesis in an unbiased way: not only is there a plethora of transgenic lines available that can be used to express optogenetic constructs in specified subsets of DANs, but there is also a wealth of sufficiently different behavioral paradigms to assess the generality of any DAN subpopulation. Combining these two assets in order to screen for the DANs mediating such 'common currency', we have tested nearly 50 different fly strains in four different experimental setups which DANs they prefer to be active and which they prefer to be silent. 


\section{Methods}

\section{Fly genetics}

To avoid visual cues from the stimulating light that would interfere with our reinforcement scores, we genetically blinded flies with a mutated no receptor potential A gene (norpA ${ }^{P 24}$ ). norpA encodes for the phosphatidylinositol-specific phospholipase $C$ that is involved in several sensory pathways. The mutation abolishes vision completely. In addition, the norpA ${ }^{P 24}$ allele decreases olfactory discrimination and impairs temperature discrimination at temperatures between $18^{\circ} \mathrm{C}$ and $26^{\circ} \mathrm{C}$.

We crossed the norpA mutants with 20xUAS-CsChrimson flies to create norpA;UASCsChrimson flies. Virgins from this stock were always crossed with male Gal4 driver lines and the blind male offspring recorded in our experiments.

\section{Fly strains used}

In total, we used 52 different fly lines in our four different screens. Of those, 13 were tested in all four screens, another 13 in three screens, 6 lines in two screens and 19 in only one screen (Tab. 1). 


\begin{tabular}{|c|c|c|c|c|c|}
\hline Fly line & RRID/FBid & Red T & $\begin{array}{l}\text { Yellow } \\
T\end{array}$ & $\mathbf{Y}$ & Joy \\
\hline $58 \mathrm{E} 02$ & BDSC_41347 & + & + & + & + \\
\hline 5HTR1B & BDSC_27636 & + & + & + & + \\
\hline MZ19 & BDSC_34497 & + & + & + & + \\
\hline NP1528 & DGGR_112679 & + & + & + & + \\
\hline NP47 & DGGR_112021 & + & + & + & + \\
\hline NP5272 & DGGR_113659 & + & + & + & + \\
\hline NP6510 & DGGR_113956 & + & + & + & + \\
\hline TH-D' & FBtp0083573 & + & + & + & + \\
\hline TH-D1 & FBtp0083568 & + & + & + & + \\
\hline TH-D4 & FBti0151783 & + & + & + & + \\
\hline TH-F2 & FBti0151786 & + & + & + & + \\
\hline TH-F3 & FBti0151787 & + & + & + & + \\
\hline TH-G1 & FBti0151784 & + & + & + & + \\
\hline GR28BD+TRPA1 & & - & + & + & + \\
\hline DDC(HL8) & & - & + & + & + \\
\hline MB025B & BDSC_68299 & - & + & + & + \\
\hline MB056B & BDSC_68276 & - & + & + & + \\
\hline MB065B & BDSC_68281 & - & + & + & + \\
\hline MB109B & BDSC_68261 & - & + & + & + \\
\hline MB304B & BDSC_68367 & - & + & + & + \\
\hline MB315C & BDSC_68316 & - & + & + & + \\
\hline MB299B & BDSC_68310 & - & + & + & + \\
\hline MZ840 & FBti0004385 & + & + & + & - \\
\hline $\mathrm{TH}-\mathrm{C} 1$ & FBtp0083567 & + & + & + & - \\
\hline $\mathrm{TH}-\mathrm{F} 1$ & FBti0151785 & + & + & + & - \\
\hline DDC(HL9) & & + & + & - & + \\
\hline $\mathrm{TH}$ & BDSC_8848 & + & + & - & + \\
\hline MB032B & BDSC_68302 & - & + & + & - \\
\hline MB060B & BDSC_68279 & - & + & + & - \\
\hline MB312B & BDSC_68314 & - & + & - & + \\
\hline $\mathrm{TH}-\mathrm{C} 1+\mathrm{TH}-\mathrm{F} 1$ & & - & + & - & + \\
\hline TH-G4+TH-G80 & & - & + & - & + \\
\hline C259 & FBti0072288 & + & - & - & - \\
\hline GR66A & BDSC_57670 & + & - & - & - \\
\hline GR66A(Co) & & + & - & - & - \\
\hline $\mathrm{TH}-\mathrm{C}^{\prime}$ & & + & - & - & - \\
\hline GR28BD+TRPA1(Co) & & - & - & + & - \\
\hline 58E02+THG80 & & - & - & + & - \\
\hline 5HTR1B+CHAG80 & & - & - & + & - \\
\hline
\end{tabular}




\begin{tabular}{|l|c|c|c|c|c|}
\hline C061 & BDSC_30845 & - & - & + & - \\
\hline MB058B & BDSC_68278 & - & - & + & - \\
\hline MB301B & BDSC_68311 & - & - & + & - \\
\hline MB438B & BDSC_68326 & - & - & + & - \\
\hline MB439B & BDSC_75961 & - & - & + & - \\
\hline MZ19+CHAG80 & & - & - & + & - \\
\hline MZ840N+P6510 & & - & - & + & - \\
\hline NP2758 & DGGR_104313 & - & - & + & - \\
\hline NP47+CHA-G80 & & - & - & + & - \\
\hline NP5272+MZ840 & & - & - & + & - \\
\hline NP6510+NP5272 & & - & - & + & - \\
\hline TH-G4+CHA-G80 & & - & - & + & - \\
\hline
\end{tabular}

Table 1. Fly lines used in which experiment. Also see (Aso et al., 2012) for unlisted stocks.

We targeted as many different DAN subpopulations in as many dopamine clusters as possible. Historically, there were more broadly expressing driver lines and subsequent, more recently developed narrow driver lines, focusing mostly on DANs with projection in the mushroom bodies (Fig. 1). Flies without mushroom bodies have no problems expressing preferences and can learn most tasks quite well, except when they involve odors (Putz and Heisenberg, 2002; Wolf et al., 1998). Thus, there is no reason to assume the mushroom bodies themselves are involved in operant activity in any way. On the contrary, the current literature suggests they should be dispensable. Instead, the focus on this neuropil structure derives from a combination of the availability of transgenic lines and the preponderance of DANs to target the mushroom bodies. For instance, DANs targeting mushroom bodies have been 
widely used in classical olfactory conditioning experiments, where they are thought to mediate a valuation signal, through which the unconditioned stimulus (US) transfers its response-eliciting properties to the conditioned stimulus (CS) (Liu et al., 2012; Qin et al., 2012; Schwaerzel et al., 2003; Yamagata et al., 2015). Here, we test the hypothesis that such reinforcing or punishing DAN functions generalize to situations beyond a classical US, or whether they merely serve to convey value to an external, likely olfactory stimulus (i.e, in world-learning (Brembs, 2011; Brembs and Plendl, 2008; Colomb and Brembs, 2010)).

A

MB-projecting G4

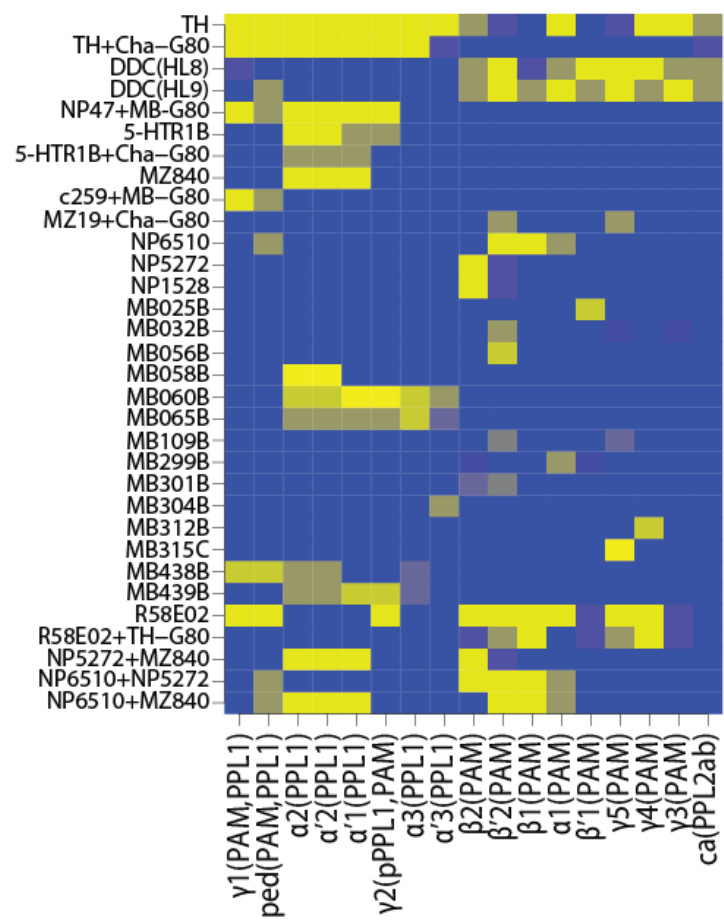

Broader G4

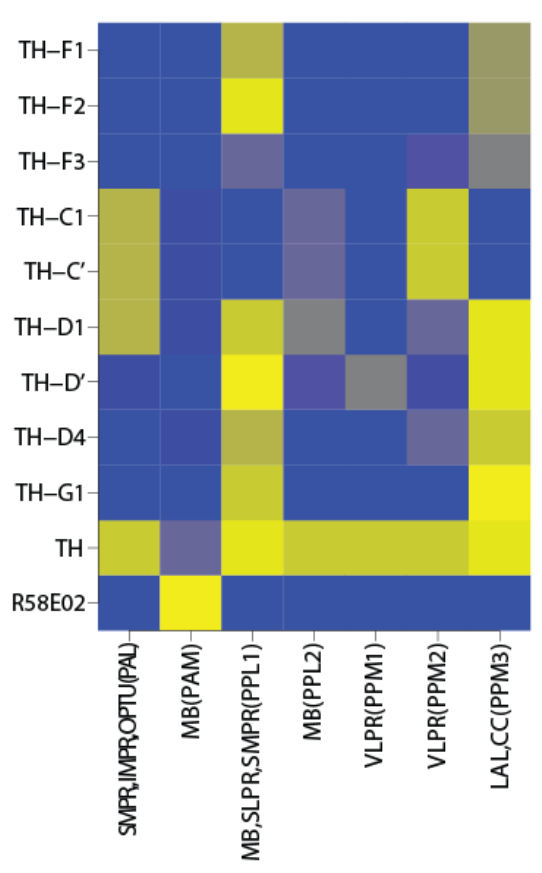

$\stackrel{\circ}{\circ}$

$\stackrel{\infty}{\circ}$

$\stackrel{20}{0}$

g

รี

$\therefore$ 
Figure 1: Schematic depiction of DAN driver line expression patterns.

Normalized reporter expression intensity from blue (zero) to yellow (one) for each driver line used (vertical axis, see Tab. 1) and their anatomical coverage (horizontal axis; DAN clusters with their projection sites and cell body location, within brackets). A: Mushroom-body projecting driver lines obtained from (Aso et al., 2014, 2012, 2010) with their corresponding expression pattern. B: Driver lines expressing more broadly than just mushroom-body projecting DANs from (Liu et al., 2012; Pathak et al., 2015). The expression pattern was estimated from (Galili, 2014; Liu et al., 2012; Pathak et al., 2015).

\section{Fly care and reagents}

Male Gal4 drivers and norpA ${ }^{P 24} ; 20 x U A S-$ CsChrimson effector virgin flies were kept overnight on standard cornmeal and molasses food medium (Guo et al., 1996) in darkness at $25^{\circ} \mathrm{C}$ and $60 \%$ humidity for egg laying. One to six days after hatching, groups of approx. 30 male offspring were put in small glass vials with all-trans-retinal (ATR) supplementation for two days before testing. For feeding ATR, $15 \mu \mathrm{l}$ of $200 \mathrm{mM}$ ATR dissolved in ethanol were pipetted onto the surface of $10 \mathrm{ml}$ of food. With these procedures, we ensured that the flies' first encounter with light was during the experiment. For each setup, pilot experiments determined light intensity and stimulation frequency using a positive control together with a negative control of the same, age-matched genotype, but without ATR in the food. Light parameters were empirically calibrated until the positive control showed a robust effect size relative to the negative control.

In our very first experiments, using the Tmaze with red light (Fig. 2A), we used nor$p A^{P 24} ;$ Gr66a $>$ CsChrimson, as positive control. This 
line expresses CsChrimson in bitter taste neurons and their activation mediates avoidance (Marella et al., 2006; Stern et al., 2019). The aversive effects we obtained were of moderate size and so we sought to improve on these controls. In all subsequent experiments, we used nor$p A^{P 24} ; G r 28 b d+\operatorname{TrpA1}>$ CsChrimson as positive controls. These flies express the Chrimson channel in heat sensitive neurons which also mediate aversion. The combination of Gr28bd with TrpA1 drivers showed stronger aversion than Gr66a in our experiments and therefore was used for all further experiments. Whereas Gr28bd expresses in heat sensitive neurons in the arista of the antennae, $\operatorname{TrpA1}$ expresses in the heat sensitive neurons in the brain $A C$ neurons.

Light was measured with a lux meter (Table 2). To confirm that the light spectrum specified in the light source data sheet was correct, the stimulation light was measured with the spectrophotometer at the place where the fly would perceive it (Table 2 ). 
bioRxiv preprint doi: https//doi. org/10.1101/2021.10.04.463010; this version posted October 202021 . The copyright holder for this preprint (which was not certified by peer review) is the author/funder, who has granted bioRxiv a license to display the preprint in perpetuity. It is made available under aCC-BY 4.0 International license.

\begin{tabular}{|c|c|c|c|}
\hline Product & Company & URL & $\begin{array}{l}\text { article } \\
\text { number }\end{array}$ \\
\hline $\begin{array}{l}\text { Cosine Corrector for SMA-Con- } \\
\text { nectorized Fiber }\end{array}$ & Thorlabs & $\begin{array}{l}\text { https://www.thorlabs.com/newgrouppage9.cfm?object- } \\
\text { group id=3482\&pn=CCS200 }\end{array}$ & CCSA1 \\
\hline $\begin{array}{l}\text { Wide range spectrometer } 200- \\
1000 \mathrm{~nm}\end{array}$ & Thorlabs & $\begin{array}{l}\text { https://www.thorlabs.com/thorproduct.cfm?partnum- } \\
\text { ber=CCS200\#ad-image-0 }\end{array}$ & $\begin{array}{l}\text { CCS200/ } \\
M\end{array}$ \\
\hline $\begin{array}{l}\text { Coherent FieldMaxII-TO Laser } \\
\text { Power Meter }\end{array}$ & Edmund Optics & $\begin{array}{l}\text { https://www.edmundoptics.de/lasers/laser-measure- } \\
\text { ment/laser-power-meters/coherentreg-fieldmaxii-to-la- } \\
\text { ser-power-meter }\end{array}$ & \#88-411 \\
\hline $\begin{array}{l}\text { all trans-Retinal powder, } \\
>=98 \%\end{array}$ & Sigma & $\begin{array}{l}\text { http://www.sigmaaldrich.com/catalog/prod- } \\
\text { uct/sigma/r2500 }\end{array}$ & R2500 \\
\hline $\begin{array}{l}\text { Osram Oslon SSL } 145 \mathrm{Im} \text { yellow } \\
10 \times 10 \mathrm{~mm} \text { platine LEDs }\end{array}$ & Osram & $\begin{array}{l}\text { https://www.leds.de/osram-oslon-ssl-smd-led-mit- } \\
\text { 10x10mm-platine-145Im-gelb-69643.html }\end{array}$ & 69643 \\
\hline $\begin{array}{l}\text { Osram Oslon SSL } 80 \mathrm{~lm} \text { blue } \\
10 \times 10 \mathrm{~mm} \text { platine LEDs }\end{array}$ & Osram & $\begin{array}{l}\text { https://www.leds.de/osram-oslon-ssl-smd-led-mit- } \\
\text { 10x10mm-platine-80lm-blau-69635.html }\end{array}$ & 69635 \\
\hline Philips Lumileds red LEDs & Philips & $\begin{array}{l}\text { http://de.mouser.com/ProductDetail/Philips-Lu- } \\
\text { mileds/LXM3-PD01/?qs=sGAEpiM- } \\
\text { ZZMu4Prknbu83y5qjVwwqxj2nEpXknzdNQZg\%3d }\end{array}$ & $\begin{array}{l}\text { LXM3- } \\
\text { PD01 }\end{array}$ \\
\hline Digital Luxmeter 0-400000lx & Voltcraft & $\begin{array}{l}\text { https://www.conrad.de/de/luxmeter-voltcraft-lx-1108- } \\
\text { bis-400000-Ix-kalibriert-nach-werksstandard-ohne-zer- } \\
\text { tifikat-121885.html }\end{array}$ & $\underline{L X}-1108$ \\
\hline Camera Pointgrey Firefly MV & Pointgrey & https://www.ptgrey.com/firefly-mv-usb2-cameras & $\begin{array}{l}\text { FMVU- } \\
\text { 03MTC-CS }\end{array}$ \\
\hline $\begin{array}{l}\text { Voltcraft DC Power Supply 1,5 } \\
\text { to } 15 \mathrm{~V}\end{array}$ & Voltcraft & http://www.voltcraft.com/de/labor-netzgerate/ & \\
\hline $\begin{array}{l}\text { Grass Instrument S44G Square } \\
\text { Pulse Stimulator }\end{array}$ & Grass Instruments & & \\
\hline Monofilament Line & $\begin{array}{l}\text { Cormoran Seacor } \\
\text { Schockleader }\end{array}$ & $\begin{array}{l}\text { http://www.cormoran.de/co/de/produkte/an- } \\
\text { gelschn\%C3\%BCre/seacor shock- } \\
\text { leader/5,1,62,63,1,1 products- } \\
\text { model.htm?ovs prdrows2=10\&sid=btarcbwsn\&stamp= } \\
1513450435\end{array}$ & \\
\hline IR LED panel & Luminous Film & $\begin{array}{l}\text { https://www.luminousfilm.com/custom-led-mod- } \\
\text { ules.htm }\end{array}$ & \\
\hline
\end{tabular}

Table 2. Equipment used and procurement sources 


\section{Screens}

T-maze

The T-mazes are composed of a core and three removable tubes (Fig. 2A, B). The core contains an elevator for transferring the flies from the entrance tube (top) to the choice tubes (bottom). At the choice point, the flies had two options: either approach the dark arm or the arm with the optogenetically stimulating light (Fig.2A, B). LEDs were adjusted for the light stimulation with a Grass frequency generator and a power supply (Table 2). LEDs were glued to a cooling plate to avoid overheating.

We performed two screens, one with red and another with yellow light (Fig. 2A, B). The peak light intensities were 1600 lux and 1000 lux for the red $(660 \mathrm{~nm})$ and yellow (590nm) T-maze experiments, respectively, as measured at the point of the transparent arm of the T-maze. The rest of the parameters were the same for both T-maze experiments: $10 \mathrm{~ms}$ pulse width, $20 \mathrm{~Hz}$ stimulation frequency and $9.9 \mathrm{~ms}$ cycle duration with $1 \mathrm{~ms}$ delay.

Thirty or more flies were introduced in the entrance arm for the experiment. By tapping the T-maze, flies were introduced into the elevator, which then was shifted to a middle point for 30 
seconds for the adaptation of the flies. The elevator was then pushed all the way down, letting the flies move freely within the choice arms. After one minute, flies in each arm were tallied under $\mathrm{CO}^{2}$.

The same groups of flies were tested in two consecutive days for the screen with red light. Since the counting was done under $\mathrm{CO}^{2}$, and $\mathrm{CO}^{2}$ exposure may impair the flies, a day of recovery was provided before the second experiment. Experiments with the yellow light were conducted without repetition and scored in blind by two experimenters in parallel in order to obtain an estimation of the handling variability. 
A

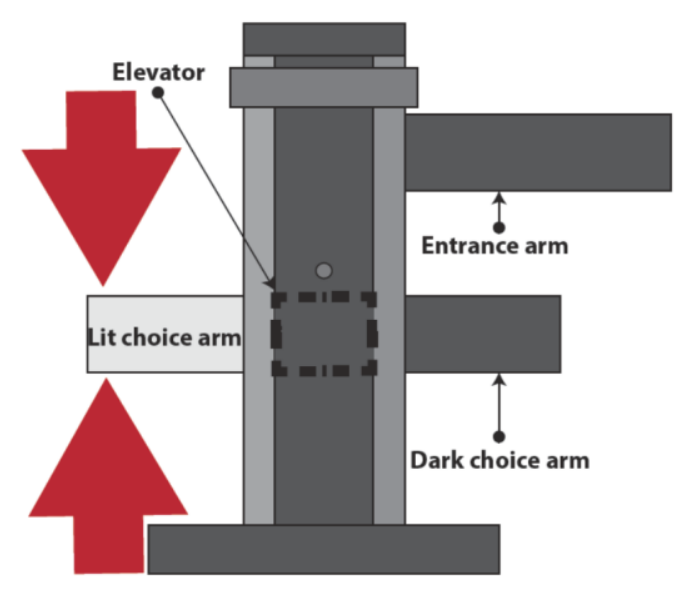

C

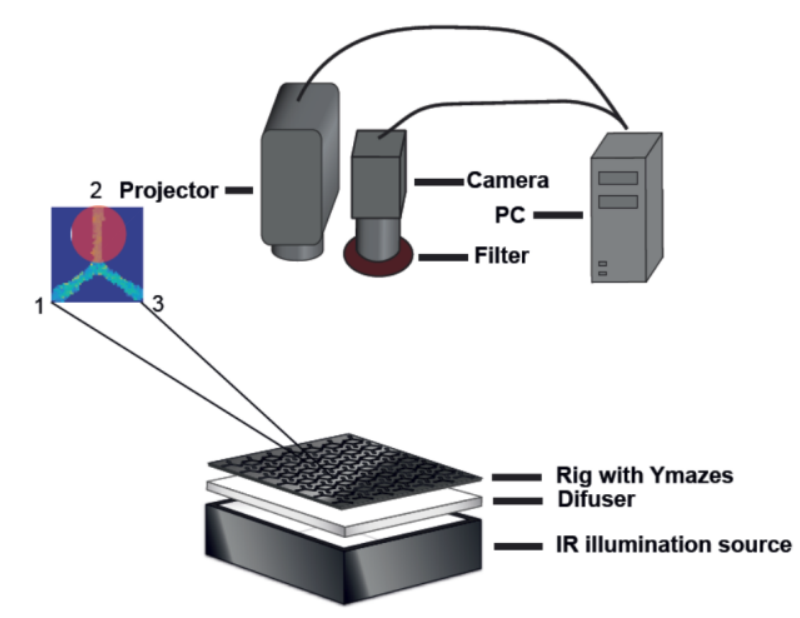

B

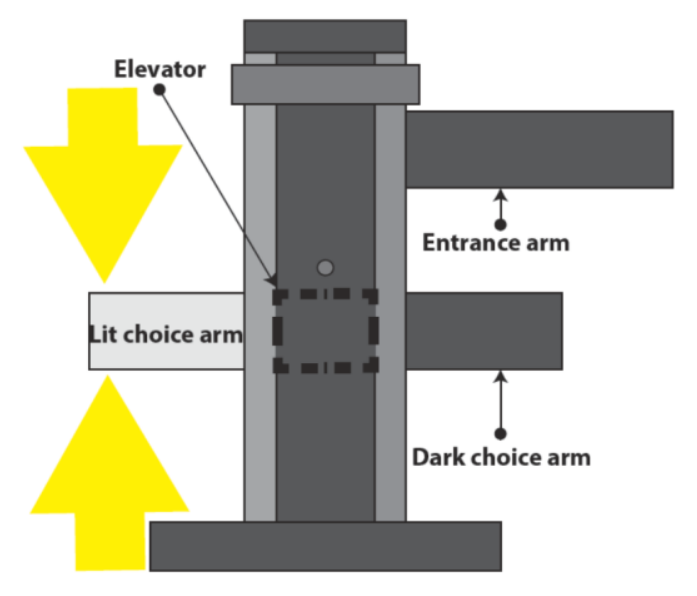

D

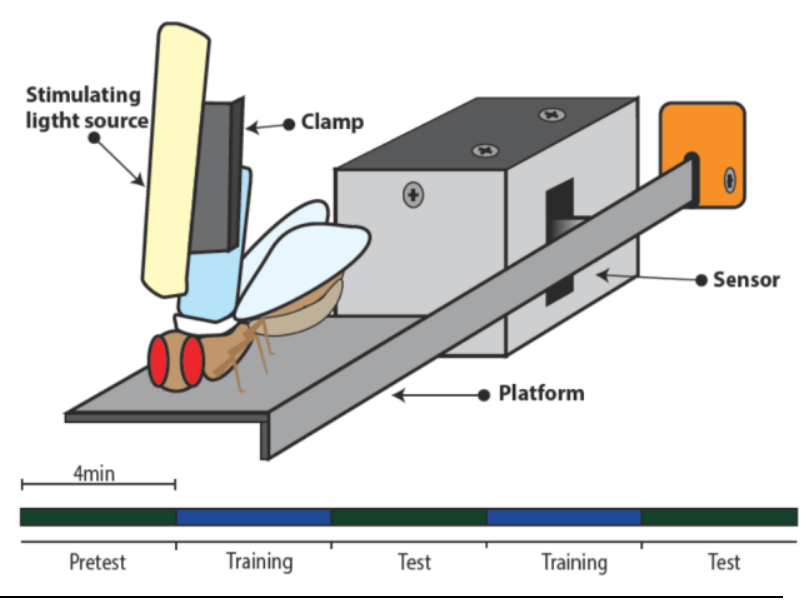

Figure 2: Schematic depiction of the four experimental setups.

A-B: T-maze schematics. Animals were first loaded into the entrance arm. After acclimatization, they were tapped into the elevator that transported them to the choice point. A: Red light was used for optogenetic stimulation (see Materials and Methods for details). B: Yellow light was used for optogenetic stimulation (see Material and Methods for details). C: Y-mazes schematics. The Y-mazes are illuminated from below and fly behavior is recorded from above. A PC processes the camera image online and switches the projector's red light for Y-maze arm illumination (enlarged inset) for closed-loop feedback. D: Joystick schematics. The tethered flies control the position of the platform with their legs. A sensor records platform position and a PC makes yellow optogenetic light (via a lightguide) contingent on platform position, which effectively serves as a switch for the light. Bottom: experimental design: 'training' denotes periods where the fly controls the light, 'test' denotes periods where the light is permanently switched off. 


\section{Y-mazes}

The setup consisted of a Perspex block $(30 \times 35 \mathrm{~cm})$ containing $120 \mathrm{Y}$-mazes. The Y-mazes were backlit with an infrared LED panel (Table 2) and a diffuser to scatter light homogeneously, as previously described (Buchanan et al., 2015). In each Y-maze, a single fly freely explored the three arms, one of which was illuminated with the optogenetically stimulating red light coming from a projector placed next to the camera tracking the flies' position (Fig. 2C).

The positive control showed the strongest phenotypes at $80 \%$ and $100 \%$ of the maximum projector light intensity. Therefore, the light intensity was set to its maximum. Light was set at [ $\left.\begin{array}{lll}1 & 0 & 0\end{array}\right]$ (RGB code) and its spectrum ranged from $570 \mathrm{~nm}$ to $720 \mathrm{~nm}$ with a peak at $595 \mathrm{~nm}$. Light stimulation frequency was set at that of the projector $(75 \mathrm{~Hz})$, and sampling frequency was set to $37.5 \mathrm{~Hz}$, half of the refresh rate of the projector (Table 2), in order to avoid light display inaccuracies. The duty cycle was $50 \%$.

Fly behavior was recorded with a digital camera and further processed with background subtraction in Matlab (Mathworks) to obtain simultaneous tracking of the 120 flies. A 850nm long pass filter (Table 2) was placed in front of the camera to avoid interference of the stimulating light 
in the tracking (Buchanan et al., 2015; Werkhoven et al., 2019).

All the Matlab scripts were run under Matlab version 2015a under Windows 7. The projector stimulation patterns were designed with Psychtoolbox-3 toolbox (http://psychtoolbox.org/) with its third-party dependencies and an Nvidia graphic card.

Closed-loop stimulation with the projector demanded enough spatial resolution to display light in specific Y-maze arms. This required the pixels of the projector to match those on the camera. To achieve this with high accuracy, the projector displayed a black and white pattern on a white surface that was captured by the camera. These patterns were used to calibrate projector pixels in camera coordinates. For every calibration procedure, at least an $\mathrm{R}^{2}=0.9998$ in the projector-camera pixels correlation was accomplished (approx. pixel precision).

The experiment protocol consists of a total of 60 minutes test where each of the arms was reinforced for 20 minutes by displaying light on the arms whenever the fly entered the given arm.

Acquisition software: https://github.com/chiser/autoTrackerV2-old-version-

Registration scripts: https://github.com/chiser/Registration-Camera-Projector

For example videos of Y-Maze function see (Werkhoven et al., 2019). 
Flies tethered by $0.7 \mathrm{~mm}$ diameter monofilament line (Table 2) glued to the tergite of their thorax were placed on a movable platform (Fig. 2D). The flies were able to use their legs to position the platform laterally with respect to their longitudinal body axis. A light guide directed the stimulating light to the fly head. Platform position is measured by a photoelectric detector that sends an analog signal ( -5 to $+5 \mathrm{~V})$ to the AnalogDigital converter.

The closed-loop stimulation is controlled by an Arduino Uno. The stimulating light intensity was 400 lux, $20 \mathrm{~Hz}, 50$ ms pulse width and no cycle delay. The custom data acquisition software was written in Visual Basics (Microsoft) and collected data with a $20 \mathrm{~Hz}$ sampling rate. As in the T-maze with yellow light, the fly line identity was blinded to experimenters to avoid ad hoc bias. The experiments were conducted by two experimenters in parallel.

In a spaced training protocol, four-minute periods of open- (green) and closed loop (blue) were alternated. In the closed loop/reinforcement period flies are trained by turning on the stimulating light when the fly pushes the platform to a specified side. The experiment protocol lasts for 20 min with alternating 4 min segments of 
Pretest, Training, Test, Training, Test. The reinforced side (right/left) was alternated at each consecutive experiment.

Joystick example video: https://www.youtube.com/watch?v=z2uOIVYrC0o

The instructions sheet with software (software originally from Reinhard Wolf, Würzburg): https://github.com/chiser/Joystick-acquisition-software

\section{Data analysis}

Since the raw data format was different for each experiment, each data set was analyzed with different sets of code to obtain a score that allows comparison across setups. Hence, every score ranges from -1 to +1 , where negative scores indicate light avoidance, positive scores approach, and close to zero scores indicate no preference for the light.

T-mazes

For the T-maze we calculated a Choice Index, $\mathrm{Cl}$ :

$$
C I=\frac{x-y}{x+y}
$$

where $x$ denotes the number of flies in the bright choice arm and $y$ the number of flies in the dark choice arm. The flies that did not make any choice and were caught in the elevator were not considered in the equation for two main reasons: locomotor deficits would impair the flies approaching any of the arms and thus not show 
their preference and it is questionable whether the light intensity in the middle is over the activation threshold for CsChrimson. From the single experiment $\mathrm{Cls}$ we calculated the arithmetic mean:

$$
\underline{C I}=\frac{\sum_{i=1}^{n} C I_{i}}{n}
$$

Where $n$ denotes the total number of experiments.

Y-mazes

For the Y-mazes we calculated the arm occupancy index (OI). Only flies with at least 14 turns/arm changes were used for the analysis and speed was downsampled by window averaging to $3.75 \mathrm{~Hz}$ to reduce noise.

$$
O I=\frac{x-y}{x+y}
$$

where $x$ refers to time spent in the lit arm and $y$ refers to the mean occupancy in the dark arms, respectively.

Joystick

For the Joystick we calculated the Preference Index, PI, for each of the experimental periods by:

$$
P I=\frac{x-y}{x+y}
$$


where $x$ denotes the number of data points when the light is on and $y$ the number of data points in the dark. To reduce the effects initial biases may have on the training PIs, we normalized the average training PI by subtracting the pretest PI from it. In addition, we measured the platform wiggle as a proxy for general activity:

$$
\text { wiggle }=\sum_{n=1}^{N}\left|\frac{d x}{d(t-20)}\right|
$$

where $x$ denotes the time-stamped platform position and $t$ the time stamp. The time series was differentiated with a lag of 20 to capture the wiggle at a slower time scale that corresponded more closely to the fly behavior. We subtracted the wiggle scores during lights off to when lights were on, obtaining a ratio that is positive when flies move more during neuronal activation, and vice versa. The wiggle score was used to exclude inactive flies from the data analysis. The wiggle cut-off was set at 0.8 .

\section{Rescreens}

T-Maze with yellow light

In rescreening the two most consistent lines from our 13 lines which were tested in all four screens, TH-D1 and TH-D', we used the exact same experimental parameters as in the original screen. We tested a total of seven experimental 
groups. The positive control Gr28bd+TrpA1 and the two experimental groups TH-D1 and TH-D' were complemented by four control groups. The genotypes of the positive control and the two experimental groups were also tested without ATR supplementation, and to control for potential insertion effects of the effector alone, we tested $\mathrm{w}^{1118}$;UAS-CsChrimson without ATR. Data analysis was also performed as in the original screen.

Rescreen. As the T-maze rescreen failed to detect significant effects in the two experimental groups, we not only adjusted our target sample size (see "Statistical Power", but we also tweaked four parameters in the experimental design of the Joystick experiment with the intention to maximize potential effects: a) We maximized the light intensity to around twice the levels used in the original screen, i.e., about 900 lux peak intensity, measured at the end of the lightguide. b) We doubled the number of training periods to eight (for a total of eight minutes continuous training, see Fig. 7, the same amount of training as in the original screen but not interspersed with test periods). c) We increased the required activity levels for inclusion in the analysis from 0.8 to 0.9. d) We performed our statistical analyses on the PIs of the final training period. Due to the large sample size (see below), we decided against normalizing 
the training PI to the pretest PI, as in the original screen. We tested the same seven experimental groups as in the T-maze rescreen (see above).

Light intensity test. In order to determine whether the increased light intensity was the cause of the inverted valences of the two experimental lines (see Results), we performed the same experiment as in the rescreen above, but with half the light intensity (i.e., 400 lux peak intensity at the end of the light guide) and without the control groups that were not supplemented with ATR. As the valences did not change, we stopped the experiment before the target sample size of 50 was reached (i.e., at $\mathrm{N}=38$ ).

Intermittency test. Original screen and rescreen differed in that the original screen alternated training and test periods, while the rescreen and light intensity test were run with continuous training without interspersed test periods (see above). In order to test whether continuous training was causing the switch in valence of $\mathrm{TH}-\mathrm{D}^{\prime}$, we tested just this line at the light intensity of the initial screen with five alternating periods each of test and training.

\section{Statistical power}

The T-maze screen with red light was the first experiment and we did not perform a power 
analysis because we did not yet know if the effect sizes of the screened lines would be of the same size as our positive controls.

We found that effect sizes afforded by the DAN driver lines were considerably smaller than those of the driver lines expressing in heat sensitive neurons. We thus had to choose effect sizes and alpha values that traded off sufficient statistical power with biologically meaningful effect sizes and practically feasible sample sizes. Therefore, we had to choose an alpha value of $5 \%$ (Lakens et al., 2018), despite otherwise routinely aiming for alpha values of $0.5 \%$ (Benjamin et al., 2018).

In the Y-mazes, data collection is automated and so many choices are recorded in so many animals that even the smallest effects are likely to be statistically significant even with $80 \%$ power at an alpha of $0.5 \%$, such that in this screen, the question is more whether small effects are biologically relevant. Therefore, we performed power analyses only for the T-maze with yellow light and the Joystick. We performed a onetailed t-test for the positive against the negative control, where the power was set to $80 \%$ and significance to 0.05 . The estimated number of experiments for the T-maze was eight. However, since the T-maze with red light suggested we may also 
be interested in smaller effects in our experimental lines, we set the target sample size to 12 .

In the T-maze rescreen, we doubled this target sample size to be able to detect the even smaller effects we observed in the two candidate lines TH-D1 and TH-D' with 80\% power at an alpha of $5 \%$. For the Joystick, the power analysis resulted in a target sample size of 15 which we did not change due to practical constraints. For the Joystick rescreen, we increased our target sample size to 50 to reach $80 \%$ statistical power for an alpha of $5 \%$ at an approximate PI of 0.2 , as suggested from the results in the initial Joystick screen.

We performed both frequentist and Bayesian tests to arrive at a combined reliability estimate, as indicated in the figure legends, given that we had to choose a relatively high alpha value of $5 \%$.

\section{Source code and data availability}

Code

Most of the analysis and plotting was done in R 3.4.2 (https://www.R-project.org), except for the data analysis of the Y-mazes, which was done in Matlab 2015a (Mathworks). Analysis scripts URLS:

Power analysis: https://github.com/chiser/power-analysis 


\section{Y-mazes: https://github.com/chiser/matlab-analysis-on-operant-reinforcement}

Joystick, T-maze yellow: https://github.com/chiser/screen-analysis-for-yellow-Tmaze-andloystick

T-maze, red: https://github.com/chiser/T-maze-drosophila

Data acquisition software and analysis scripts for the original screens are available at https://github.com/chiser

Data analysis scripts for the Joystick experiments are available at: https://github.com/brembslab/Platform-Drosophila/tree/master/Platform-Optogenetics

\section{Data}

All raw data and data evaluation sheets in a single package: https://doi.org/10.6084/m9.figshare.16635841

DOls for individual datasets provided in figure legends.

\section{Results}

\section{Robust avoidance with optogenetic feedback in all four}

\section{screens}

We performed four optogenetic screens on the appetitive or aversive functions of dopamine neuron (DAN) sub-populations in three different operant activity setups. Each screen was designed after a series of pilot experiments had been performed. In these pilot experiments, the experimental details were empirically tuned by testing an aversive driver line (at the time of these experiments, there was no suitable appetitive driver line available) as positive control with and without ATR supplementation. These experiments set the expected effect sizes according to which we estimated our target sample sizes. In 
each setup, the flies (blinded by the NorpA ${ }^{224}$ mutation) were free to choose between a situation in which the neurons selected by the driver line would be stimulated with light and one in which there was no such stimulating light. All four experiments correspond to optogenetic self-stimulation. In the T-maze with red light (Fig. 2A), we used Gr66a-Gal4 (bitter taste neurons) and in all other setups we used Gr28bd+TrpA1-Gal4 (heat sensing neurons) as positive controls. The positive controls in all four setups show the expected avoidance (negative scores), demonstrating that the basic optogenetic method was working robustly with our chosen driver lines (Fig. 3). In the two screens where we also tested positive control flies without ATR supplementation (Fig. 3A,C), these groups showed neither avoidance of nor preference for the light, demonstrating that the effects we observed were indeed due to the csChrimson optogenetic effector. 
bioRxiv preprint doi: https://doi.org/10.1101/2021.10.04.463010; this version posted October 20, 2021. The copyright holder for this preprint (which was not certified by peer review) is the author/funder, who has granted bioRxiv a license to display the preprint in perpetuity. It is made available under aCC-BY 4.0 International license.

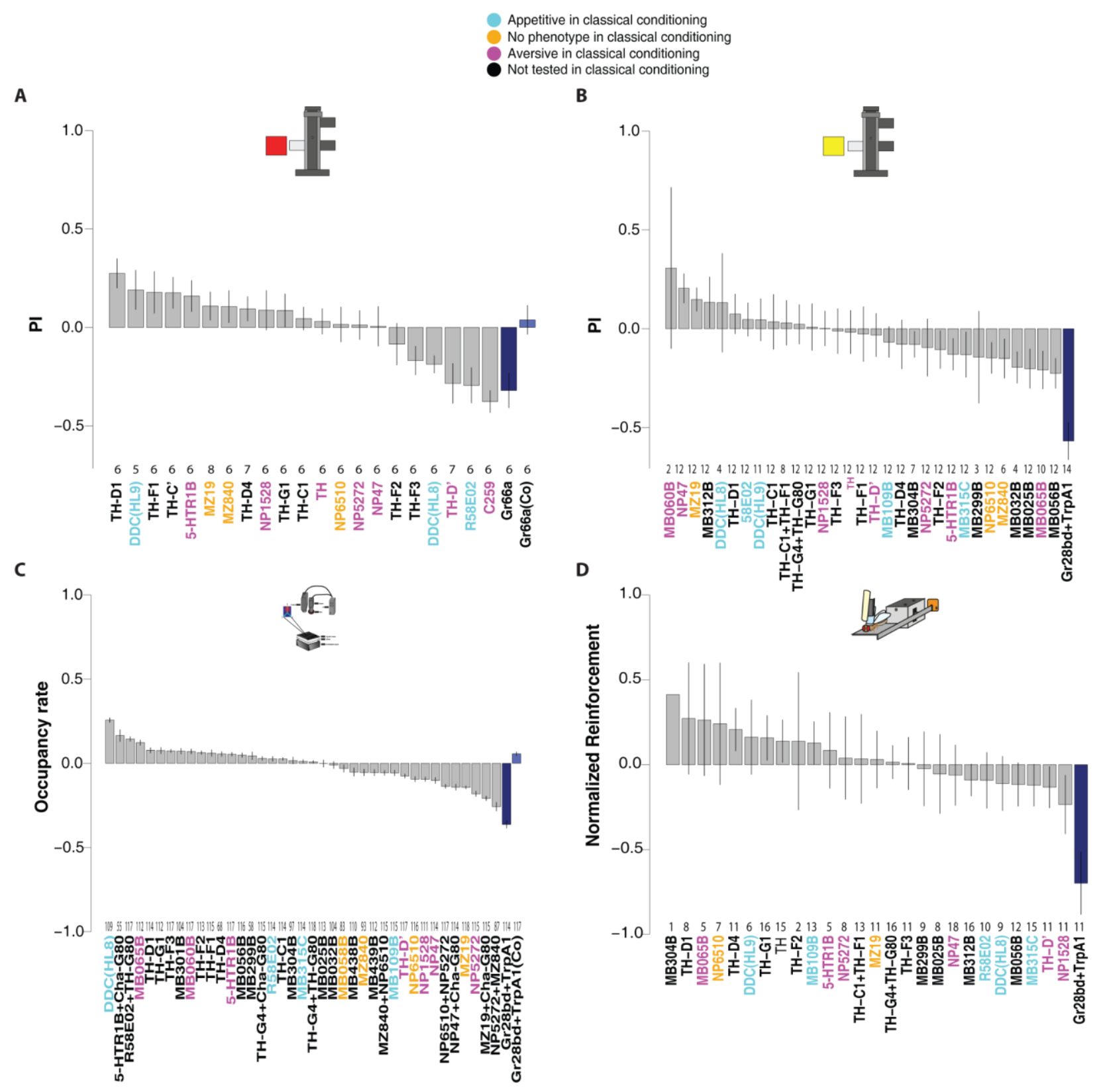

Figure 3: Operant activity screens

A: Choice indices from the T-maze screen with red light. B: Choice Indices from the T-maze screen with yellow light. C: Occupancy Indices from the Y-mazes screen. D: Joystick screen Performance Indices. Barplots depict each driver line means for each behavioral score in descending order with error bars depicting the standard error of the mean (SEM). Positive controls fed with and without ATR are coloured in dark- and light blue, respectively. Number of experiments for each line is shown above each driver line label on the X-axis. Driver line fonts are color-coded according to classical conditioning phenotypes as shown in the legend above. All lines contained a norpA ${ }^{\mathrm{P} 24}$ mutation which is omitted for simplicity.

T-maze screen spreadsheets: 10.6084/m9.figshare.16635439

Joystick screen data and evaluation sheet: 10.6084/m9.figshare.16635079

Y-mazes screen raw data and MatLab files: 10.6084/m9.figshare.16635091 


\section{DANs account for a small component of operant activ- ity}

Depending on our choice of positive control, the preferences of any of the DAN test lines could have been either larger than the positive control, of the same size, or smaller. None of our positive control lines showed such a strong aversion that any stronger aversion would have been impossible. In fact, when using bitter taste neurons (Gr66a) as positive control, there were two DAN lines with similar avoidance (TH-D' and R58E02) and one with marginally higher avoidance (C259; Fig. 3A). On the appetitive end, TH-D1 preference for light was of similar size, relative to Gr66a avoidance of the light (Fig. 3A). In contrast, in the cases where we used drivers in heat sensitive neurons as positive controls, the effect sizes were considerably higher than any of the effects observed in the DAN test strains (Fig. 3B-D).

\section{DANs serve different functions in operant than in classi- cal situations}

Given that their contribution to operant choice is relatively small, the question arises if at least the general valence in terms of appetitive, aversive or neutral is conserved, when comparing our results with those reported in the literature for classical conditioning (Aso et al., 2014, 2012, 
2010; Liu et al., 2012). Our results suggest that the ability of a DAN subpopulation to replace appetitive or aversive, respectively, unconditioned stimuli (USs) in classical conditioning experiments does not predict behavior in operant experiments: DANs that have been reported to serve as aversive USs can be both aversive or appetitive in operant situations, or provide no discernible preference (Fig. 3, lines marked in red). An illustrative example is line NP47, which avoids the light in the Y-maze, approaches it in the T-Maze with red light and shows no preference in both experiments with yellow light. In this case, the same neurons can mediate approach and avoidance depending on the situation. Another notable example is 5HTR1B which does avoid yellow light in the Tmaze but approaches red light in both the T-maze and the Y-maze. Removing cholinergic neurons from the 5-HTR1B patterns using cha-Gal80 increases the approach of the red light in the $Y$ maze to the second highest level in this screen. The $\mathrm{TH}$ line which was shown to confer aversive properties to an odor in an operant paradigm (Claridge-Chang et al., 2009), did not show any preference in any of our T-maze screens.

DANs that have been reported to serve as appetitive USs in classical conditioning, can also be appetitive, aversive or neutral (Fig. 3, lines marked in blue). An illustrative example is line 
DDC $(H L 8)$, the line with the most extreme preference for light in the Y-mazes. It avoids the red light in the T-maze and shows weak, inconsistent behavior if the light is yellow in T-maze or Joystick.

Finally, while lines reported to have no effect when used in classical conditioning experiments never showed maximal preference in our screens, some of these lines ended up close to the maximal lines in our screens, sometimes aversive, sometimes appetitive (Fig. 3, lines marked orange). For instance, line MZ19 avoided the light in the Y-mazes, but approached it in the T-mazes, while the score was nearly exactly zero in the Joystick screen.

\section{Operant DAN function is heterogeneous}

Given that the contribution of DAN subpopulations to overall operant performance was small and not consistent with classical conditioning experiments, we tested whether their function is at least consistent between operant experiments. We varied both the type of optogenetic activation and the type of operant paradigm to test how consistently DAN activation would modulate decision-making in the flies. We found that all the parameters we varied influenced DAN function. 


\section{DAN function varies with optogenetic activation}

The T-maze screen was performed with both red and yellow light (Fig. 2A,B). Wavelengths corresponding to yellow light activate CsChrimson more effectively than those corresponding to red light (Klapoetke et al., 2014). However, we did not observe an overall increase in the effect sizes for the DAN lines when tested for their preference in a T-maze with yellow light, compared to one with red light (Fig. 3A, B). If anything, the driver lines mediating aversion of the light decreased somewhat in their effect sizes. While the switch from bitter to heat-sensing neurons for the positive control yielded considerably higher avoidance, absolute effect sizes did not increase for the screened DAN driver lines.

What did change with the switch from red to yellow light was the relative performance of the lines with respect to each other. For instance, the $\mathrm{Cl}$ of TH-D1 and TH-D' lines shrunk considerably in yellow light, without changing the sign of their scores. In contrast, line MZ840 changed from appetitive (in red light) to aversive (in yellow light). Overall, the proportion of lines with aversive function increased from 6 out of 21 lines $(29 \%)$ in the red light T-maze compared to 13 out of 31 lines (42\%) in the yellow light T-maze, but this may have been due to a potential bias in the 
function of the additional lines tested. A direct comparison between the lines tested in both the red light and the yellow light T-Maze reveals no clear relationship between performance in one experiment and performance in the other (Fig. 4B). The lack of correlation between the two experiments suggests that activating CsChrimson more effectively with yellow light did not simply enhance the function the neurons were serving in the T-Maze, rather, it changed their function, even in the same behavioral context of a T-maze. 
bioRxiv preprint doi: https://doi.org/10.1101/2021.10.04.463010; this version posted October 20, 2021. The copyright holder for this preprint (which was not certified by peer review) is the author/funder, who has granted bioRxiv a license to display the preprint in perpetuity. It is made available under aCC-BY 4.0 International license.

A

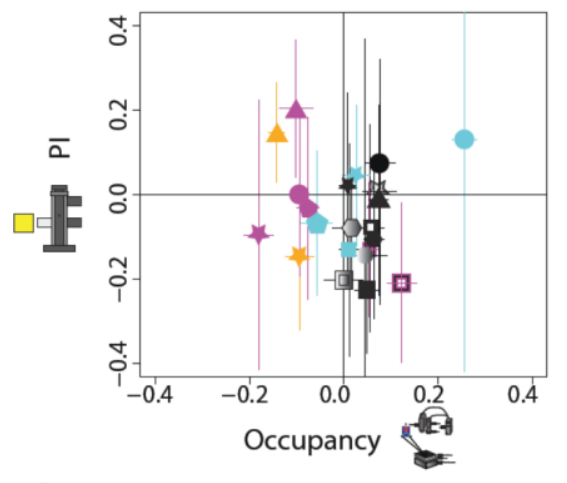

C

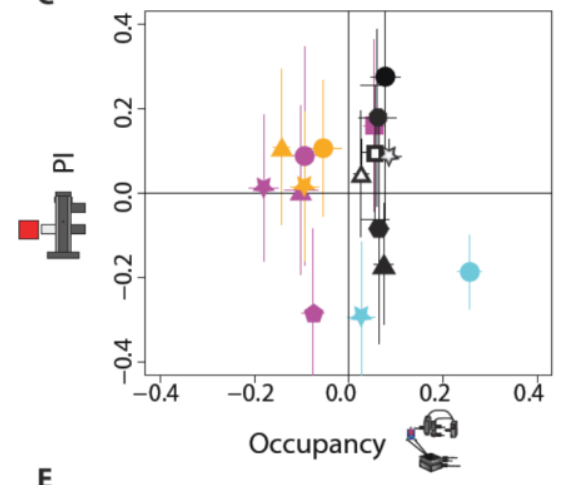

$\mathbf{E}$

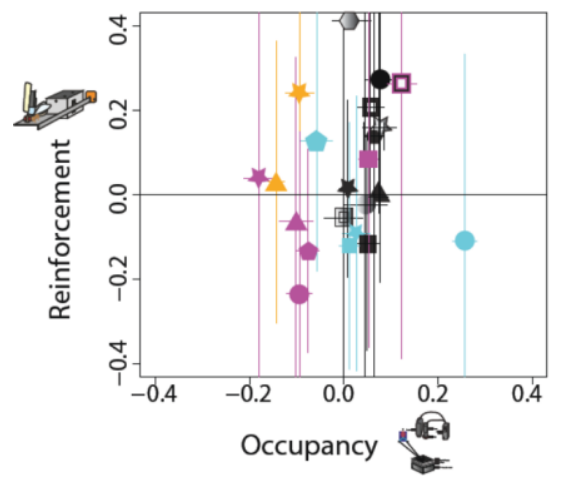

B

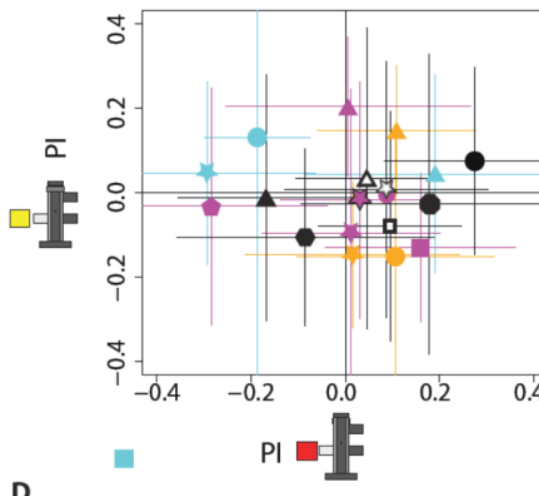

D
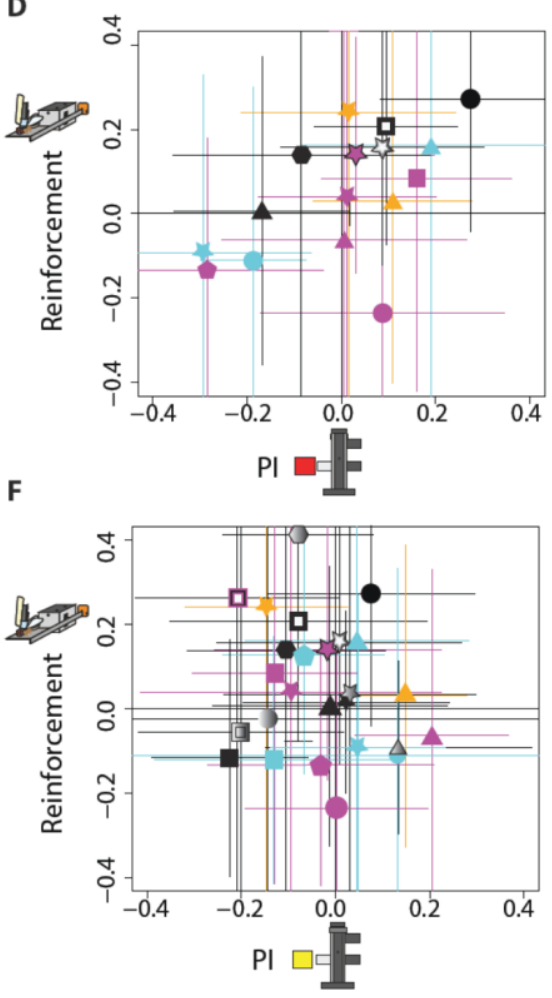

Appetitive in classical conditioning

No phenotype in classical conditioning

Aversive in classical conditioning

Not tested in classical conditioning

$\triangle \mathrm{TH}-\mathrm{C} 1$

\& TH-G1

TH-G80+TH-G4

TH-F1

TH-F2

ATH-F3

口TH-D4

$4 \mathrm{TH}-\mathrm{C} 1+\mathrm{TH}-\mathrm{F} 1$

回 MB025B

- MB56B

- MB299B

- MB304B

$\triangle \mathrm{MB} 312 \mathrm{~B}$

- MB109B

MB315C

A DDC(HL9)

R58E02

DDC(HL8)

A MZ19

- MZ840

7 NP6510

$5 \mathrm{HTR}-1 \mathrm{~B}$

NP1528

NP47

TH-D'

NP5272

口 MB065B

Figure 4: Pairwise comparison between operant activity scores.

Eight combinations of biplots projecting two behavioral axes with symbols for their means and bars indicating the SEMs for both axes. Icons depict screen type. Axes ranges were truncated to -0.4 to +0.4 for visualization purposes. Legend on the right, with colors indicating classical learning phenotypes and a corresponding symbol for each driver line.

\section{DAN function varies with group vs. individual experiment}

The T-maze is an experiment where all the flies in a group are making the same choice at the 
same time (Fig. 2A, B). The score in these experiments is calculated as the proportion of flies in the illuminated arm, proportional to the total number of flies (Choice Index). To tackle the question of whether an individual will make the same choice when it is alone versus when it is in a group, we performed an analogous forced choice test as in the group-based T-maze in Y-Mazes with individual flies (Fig. 2C). The flies ran continuously in a three-arm Y-maze where one arm was illuminated with red light. We scored the fraction of time spent in the illuminated arm. We chose this measure as it was equivalent to the Choice Index calculated for the T-maze: flies with a longer occupancy of the illuminated arm would have a larger chance of being caught and counted there in the T-maze. This change from group experiment (T-Maze with red light) to single fly experiment (Y-Maze with red light) did not yield any correlation between the scores of the flies in these experiments, not even the most extreme lines were consistent between the two situations (Fig. $4 C)$.

\section{DAN function varies with locomotion}

In all the experiments described so far, locomotion is a key component of the experiment. In fact, flies that move more slowly in the bright 
arm of the Y-Maze tend to also have a higher occupancy in this arm (Rohrsen, 2019). As biogenic amines play an outsize role in all kinds of locomotion, we tested whether operant behavior that is orthogonal to locomotion would yield different functions for our DAN subpopulations. For this test, we placed tethered flies on a manipulandum which they could move perpendicular to their longitudinal body axis using their legs (Fig. 2D). Analogous to how a human might move a joystick connected to a computer, the flies could move this platform, on which they were placed, to one side, to stimulate themselves with yellow light, while movement to the other side switched the light off. This transition from locomotion-based to locomotion-independent operant control again yielded a completely new arrangement of lines with regard to their appetitive or aversive function in operant choice (Fig. 4E). In fact, no pairwise comparison between our screens provided a convincing correlation (Fig. 4).

Considering the amount of manual labor involved, we had estimated statistical power in two of our setups (T-maze and Joystick) to detect effect sizes at most marginally smaller than those we observed in our pilot experiments with the positive control groups. Only in the Y-mazes 
screen, statistical power was sufficient to detect effect sizes substantially smaller than those of our positive controls. The small effects with DAN drivers entail that three of our screens were considerably underpowered. However, as a whole, all four of our screens might be able to identify the lines that were consistently accompanied by either appetitive or aversive behavior, respectively. Unfortunately, not all lines were tested in all setups due to a variety of technical and historical reasons (see Materials and Methods). Among those 13 that were tested in all four experiments, we searched with the lowest possible criterion of showing the same sign in their scores in all four screens. We found the lines TH-D', TH-D1 and THG1 as the only lines with consistent avoidance/attraction across all four tests. The lines TH-D' and TH-D1 were the ones with the highest absolute scores; TH-D1 behaved consistently appetitively (i.e., approaching the light) and TH-D' behaved consistently aversively (i.e., avoiding the light; see Fig. 5 for expression patterns). 

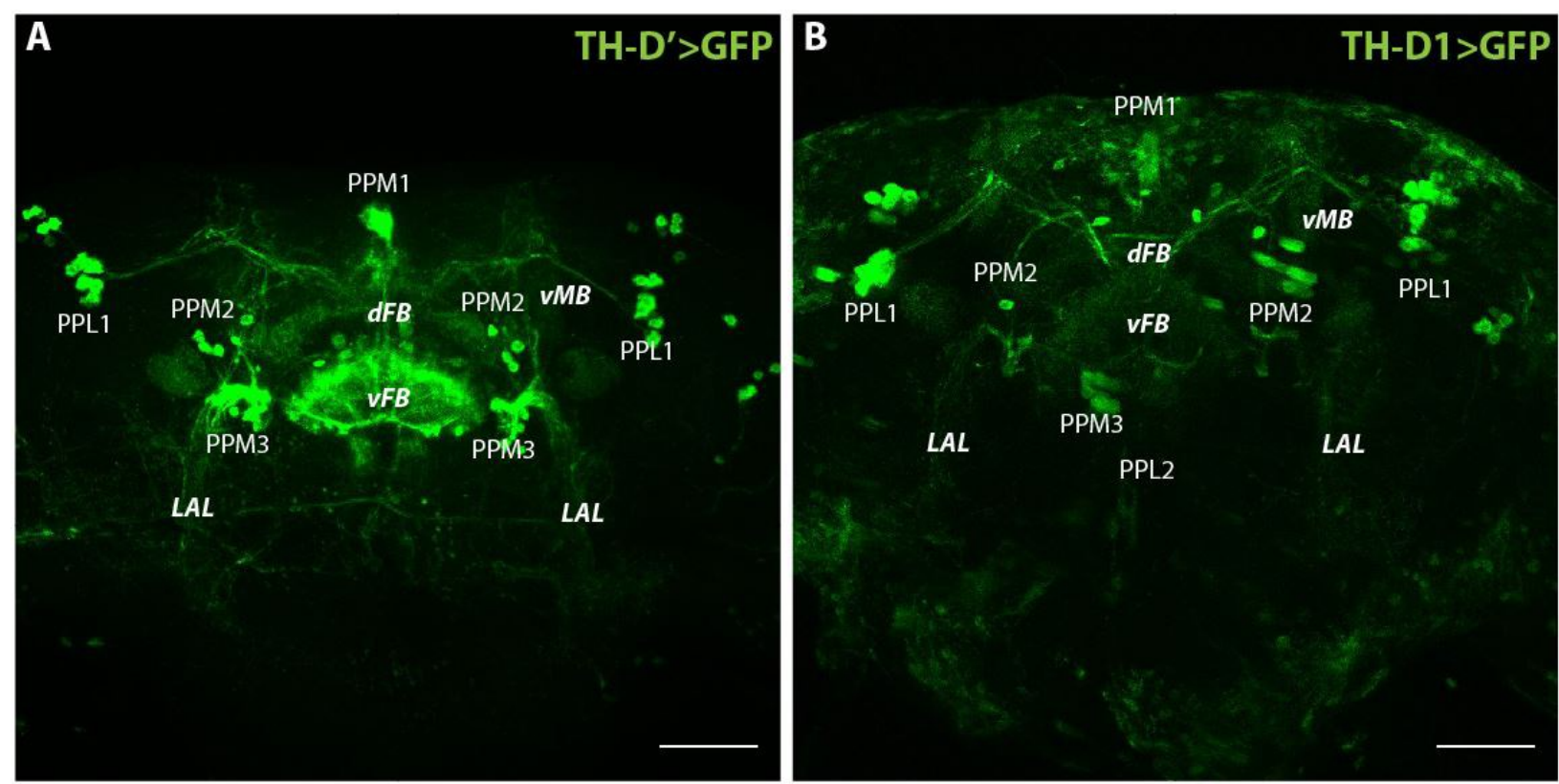

Figure 5: Expression patterns of TH-D1 and Th-D' driver lines.

The cell clusters and neuropils (bold italics) are in white. PPL: paired posterior lateral; PPM: paired posterior medial; dFB: dorsal fan-shaped body; vFB: ventral fan-shaped body; LAL: lateral accessory lobe; vMB: vertical lobes of the mushroom bodies. Scale bar $=50 \mu \mathrm{m}$.

Immunohistochemistry files: 10.6084/m9.figshare.16635448

Interestingly, the two consistent lines express in the same clusters although it was not possible to ascertain whether they labeled the same neurons (Fig. 5). Morphological features at the light microscope-level resolution are often insufficient to distinguish cell types and additional information about synaptic connectivity and genetic expression profiles are necessary to fully define cell identity (Wolff and Rubin, 2018). The cell bodies labelled belonged mostly to DAN clusters PPL1, PPM3 and PPM1 (White et al., 2010). At the neuropil level, the two lines labeled specific layers in the fan-shaped body (FB). Staining of the PPM3vFB (layer 2-4) and the noduli were particularly intense, with TH-D' FB expression being particularly 
strong. An additional FB layer from the PPL1-dFB projection was also labelled. The signal in the ellipsoid body (EB) is stronger in TH-D1 whereas the $\mathrm{LAL}$ is targeted in both lines (Fig. 5). The mushroom body $(\mathrm{MB})$ vertical lobe and pedunculus projection from the PPL1 were clearly visible as well. None of the lines stained the PAM cluster of DANs.

In order to test the hypothesis that the two most consistent lines in our four screens, TH-D1 and TH-D', are indeed reliably involved in mediating operant activity, we selected two of our four screens to rescreen these two lines with the appropriate control groups. We estimated our samples to reach $80 \%$ statistical power at an alpha level of 0.05. Because of the high alpha value, we supplement these frequentist statistics with a Bayes Factor calculation (see Materials and Methods).

\section{No DAN effects in the T-maze with yellow light}

The larger the effects in the first screens, the more likely one would expect their results to reproduce. The two lines show very robust effects in the T-maze with red light and perform at the extreme ends of our distribution of lines (Fig. 3A). While in the Y-mazes, the effect sizes are smaller, the high-powered nature of the screen makes the results there also seem quite reliable (Fig. 3C). 
Therefore, we sampled from the lowest level of the potential effect size range and began by rescreening TH-D1 and TH-D' in a T-maze with yellow light. In the original screen, the effects of driving CsChrimson with TH-D1 or TH-D' were relatively small (Fig. 3B) compared to, e.g., the effects obtained with red light in the same apparatus (Fig. 3A). The sample size in the original screen had been 12 for these two lines and our power analysis indicated that we needed to more than double our target sample size to 25 in order to decrease the mean Choice Index we would be able to reliably detect to about 0.2 . This effect size was chosen for three reasons: a) it was lying just at the edge of the variation in the original screen, b) lower levels of preference would indicate a negligible involvement even if statistically significant and c) practical reasons. At the target sample size of 25 (i.e., about 1,000 flies per group), we could not detect any effects at all in the T-maze with yellow light (Fig. 6A). Compared to their respective control groups, TH-D' showed a slight tendency to behave aversively and TH-D1 to behave appetitively, as in the original screen, but the effect sizes did not exceed control levels, let alone reach statistical significance. 

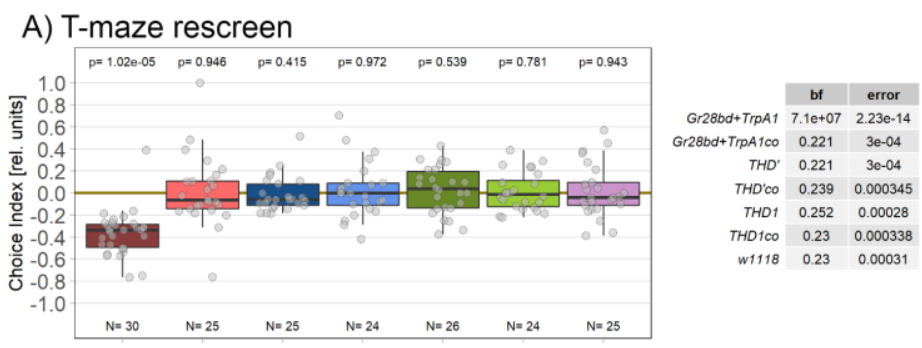

B) Joystick rescreen
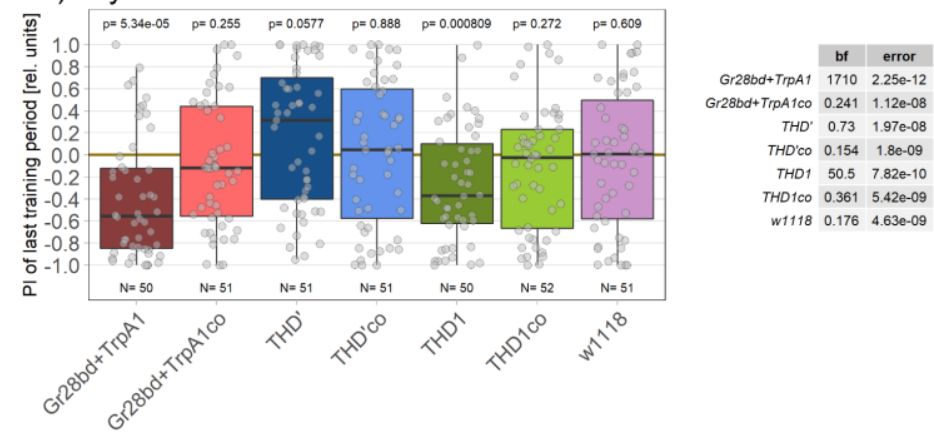

C) Joystick light intensity test

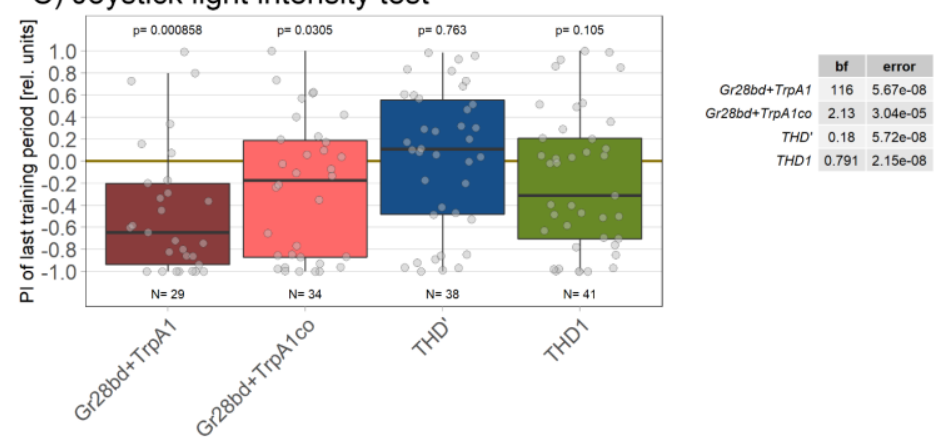

Figure 6: Rescreening TH-D1 and TH-D' reveals aversive function for TH-D1 in Joystick paradigm

A: T-maze rescreen with yellow light. Left: Choice Indices for each line. The control line Gr28bd+TrpA1 shows a statistically significant avoidance of the arm with the stimulating light, whereas all other lines do not show a defined preference. Right: The Bayes Factors of all lines except the control line are smaller than one, providing evidence in support of the null hypothesis of no preference. Together, these data strongly suggest that neither DANs in TH-D1 nor those in TH-D' support the kind of avoidance behavior that the control flies show. B: Joystick rescreen. Left: Performance Indices for each line. Both the control line Gr28bd+TrpA1 and TH-D1 show a statistically significant avoidance of light, whereas line TH-D' narrowly misses statistical significant preference of the light. All negative control lines do not show any preference, as expected. Right: The Bayes Factors corroborate the frequentist analysis: Gr28bd+TrpA1 and TH-D1 show Bayes Factors larger than one indicating rejection of the null hypothesis of no preference. Together, these data suggest that DANs in TH-D1 can support avoidance in the Joystick experiment. C: joystick light intensity test. Left: Performance Indices for each line. Stimulation light intensity was about $50 \%$ that of the Joystick rescreen (B) and matched the intensity of the original screen. Main results qualitatively reproduce those in the Joystick rescreen in terms of valence (B). Right: Bayesian analysis as above.

Boxplots depict medians (solid lines), quartiles (boxes) and non-outlier ranges (whiskers), with individual data points in grey. Sample sizes below boxplots, p-values for Wilcoxon tests against zero above.

Data for the T-maze rescreens: 10.6084/m9.figshare.16635457

Joystick rescreen data files and evaluation sheet: 10.6084/m9.figshare.16635100

Joystick light intensity test data files and evaluation sheet: 10.6084/m9.figshare.16635073 


\section{Flies use Joystick to avoid activity in TH-D1 neurons}

The two most consistent lines ended up towards the extreme ends in our Joystick screen, so we decided to continue with a rescreen in this setup. For the same reasons as above, we also aimed our power analysis for a mean Performance Index of about 0.2 , which required a target sample size of 50 in order to reliably detect this effect size. In an attempt to further maximize our chances of detecting any effects, we changed four parameters compared to the original screen (see Materials and Methods): a) We maximized the light intensity to around twice the levels used in the original screen. b) We doubled the number of training periods to eight (for a total of eight minutes continuous training). c) We increased the required activity levels for inclusion in the analysis. d) We performed our statistical analyses on the un-normalized PIs of the final training period. In this rescreen we did detect an effect in the $\mathrm{TH}$ D1 driver line and the valence of the TH-D' driver line was opposite to that of the TH-D1 line, but the TH-D' PI did neither reach statistical significance, nor did the Bayes Factor exceed the value of 1 for this group, suggesting that there was no real effect in the TH-D' line (Fig. 6B). Interestingly, the valence of both of the lines was opposite to that observed in the four original screens: In this Joystick 
rescreen, TH-D1 flies avoided the light and the trend in TH-D' flies was to switch the light on.

As increased light intensity had been shown previously to be able to change valence (Fig. 3), we performed a second experiment with the original light intensity in the Joystick setup. However, the valences were unchanged from the previous rescreen (Fig. 6C).

\section{DAN function varies with time}

A second difference in addition to light intensity compared to the original screen was the temporal structure of the experiment. While in the original screen training periods (where the flies could switch the light on and off) were interspersed with test periods (where the light was switched permanently off), the rescreen as well as the light intensity test were performed with eight consecutive training periods without intermittent test periods. Therefore, we examined the behavior of the flies during the experiment more closely. Flies with CsChrimson in heat-sensing neurons avoid the light immediately and then tend to further decrease their Pls, suggesting there is some amount of learning during the experiment (Fig. 7A). TH-D1 flies showed lower, but consistent avoidance throughout the experiment (Fig. 7B). TH-D' flies, finally, tended to switch the 
light off at the start of the experiment, only to increase their PIs gradually until the final training period (Fig. 7C). In the light intensity test (see Materials and Methods), both the generally low PI of TH-D1 as well as the increasing Pls over time in TH-D' (Fig. 7D) replicated the results from the rescreen. 


\section{A Gr28bd+TrpA1, N= 50}

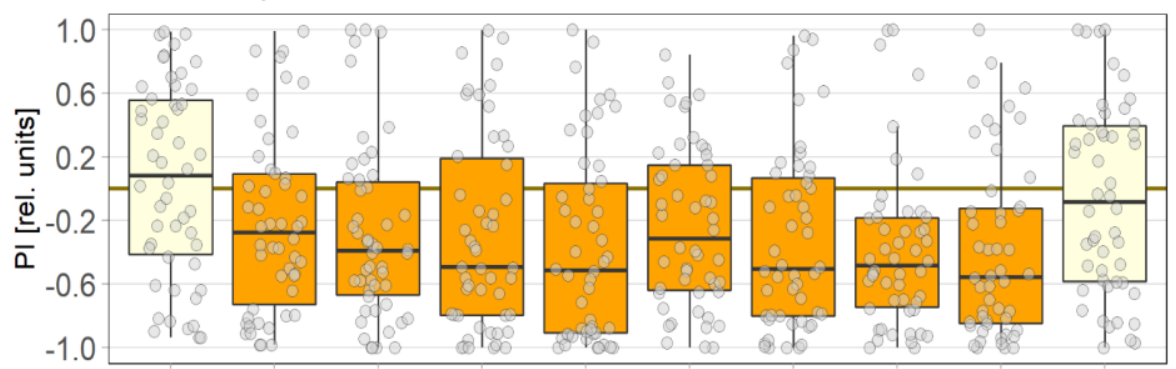

B $\quad T H D 1, N=50$

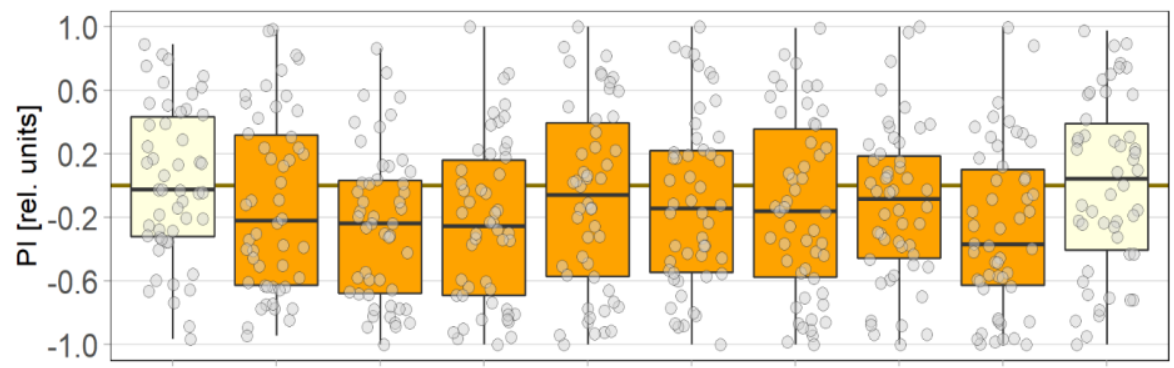

C THD', N=51

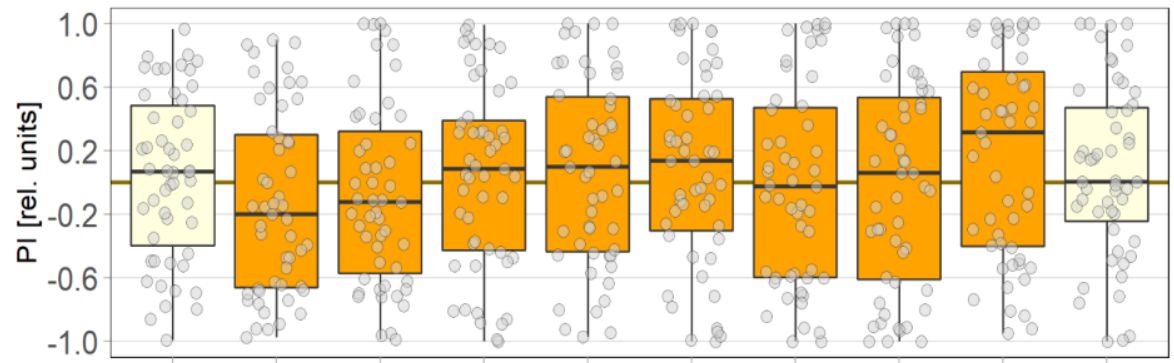

D THD', $\mathrm{N}=38$

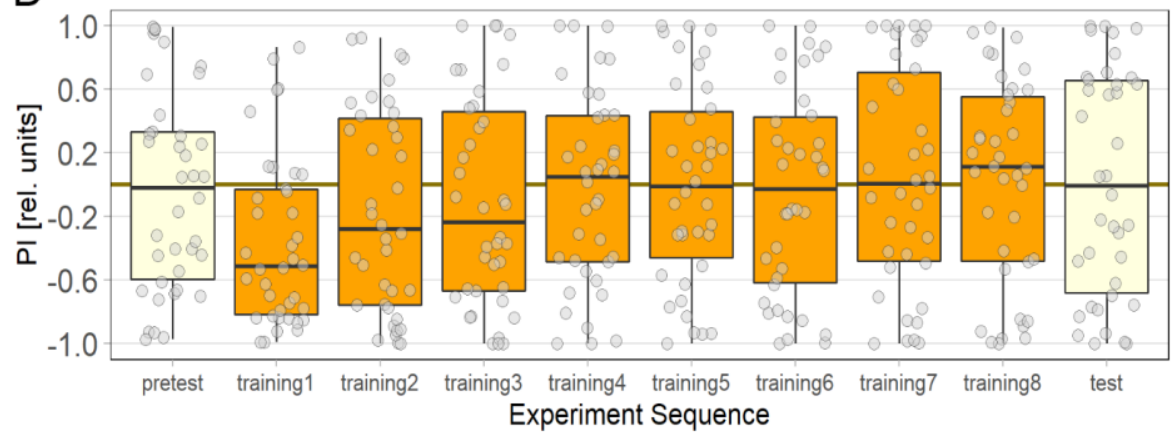

Figure 7: Time course of Joystick experiments reveals change in valence in TH-D'.

A: Control flies expressing CsChrimson in heat-sensing neurons preferentially keep the optogenetic light switched off throughout the training periods (orange), with little effect on platform position with the light permanently switched off (yellow). B: Flies expressing the optogenetic channel in TH-D1 neurons show a markedly weaker but nevertheless consistent preference for light-off during the training periods. C: Flies expressing CsChrimson in TH$D^{\prime}$ neurons at 800 lux intensity during the rescreen started their training phase by avoiding the light and finished the last training period with a slight preference for light-on. D: The same fly strain as in C tested with 400 lux intensity. The same trend from aversive to indifferent/slight preference can be observed as in $\mathrm{C}$. Time course of box plots depict medians (solid lines), quartiles (boxes) and non-outlier ranges (whiskers), with individual data points in grey. 
Pooling the rescreen with the otherwise identical light intensity test and comparing the first and the last training period reveals the shift in behavior from avoiding the light at the start of the experiment to preferring the light towards the end of training (Fig. 8). The two training periods are significantly different from each other in a U-test, the BayesFactor suggests a strong effect and the estimation statistics also indicate a shift from aversive to appetitive. In contrast to the last training period, the first training $\mathrm{PI}$ is significantly different from zero (Wilcoxon Test, $p=0.0003$, BayesFactor $=99.3)$. These analyses suggest that for the TH-D' line, brief encounters with activity in these neurons lead to aversive behaviors, such as those observed in the initial Joystick screen (Fig. 3D). We replicated these findings of the initial screen with a third Joystick experiment where we tested $\mathrm{TH}-\mathrm{D}^{\prime}$ in alternating training and test periods with the lower light intensity from the first screen (see Materials and Methods), where four out of the five training periods indeed showed a negative PI (data available at DOI 10.6084/m9.figshare.16635094). Thus, while line NP47 mediated approach and avoidance depending on the experimental situation, TH-D' DANs can change their valence over time. 

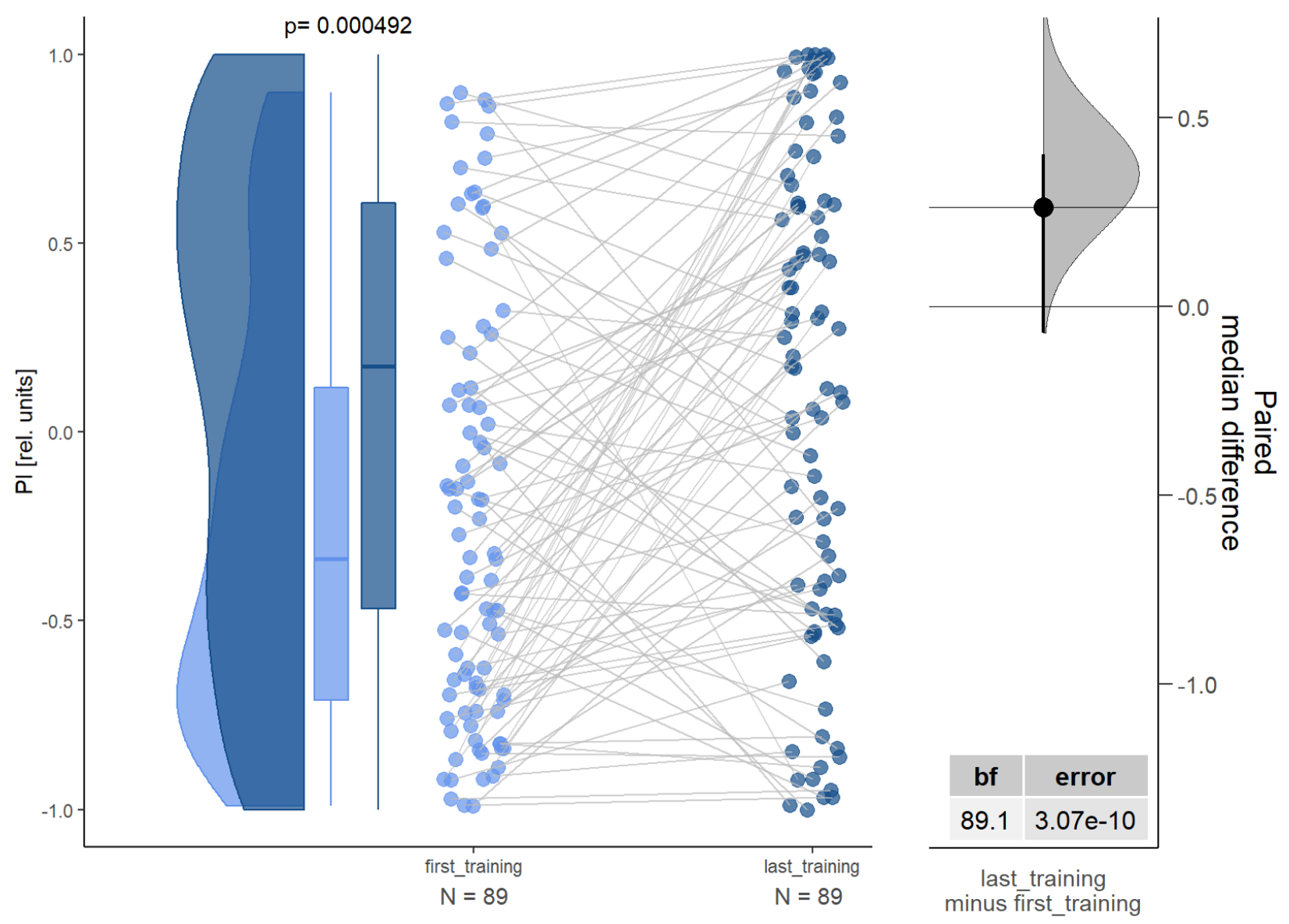

Fig. 8. First and last training differs in $T H-D^{\prime}$.

Left: Raincloud plot with violin plot, box/whisker plot and paired individual data plot of the first training period (light blue) and the last one (dark blue). Right: Estimation statistics: Paired median difference of last_training $(\mathrm{n}=$ 89) minus first_training $(n=89) 0.261[95 \% \mathrm{Cl}=-0.0699 ; 0.401]$, with Bayes Factor (bf).

Pooled THD' Joystick raw data and evaluation sheet: 10.6084/m9.figshare.16635076

Taken together, these results show a weakly aversive function for the TH-D1 line in the Joystick experiment (Fig. 5) that does not generalize to other experiments and an initially aversive function for TH-D' that can change towards appetitive under prolonged duration of operant control (Fig. 8). The initial aversive function does seem to generalize to other operant experiments. The switch from aversive to more appetitive function 
appears to generalize across different stimulation intensities (Fig. 7).

\section{Discussion}

\section{No 'common currency' DAN function in flies}

If specific DANs contribute to 'common currency' value computations (Berridge and Kringelbach, 2015; Grabenhorst and Rolls, 2011; Kobayashi and Hsu, 2019; Lak et al., 2014; Landreth and Bickle, 2008; Levy and Glimcher, 2012; Matsumoto et al., 2016; Schultz et al., 2015) also in flies, our screen of about 50 sub-populations of DANs is the currently best way to discover which DANs are involved in which value computation. Moreover, by deploying four different operant screens, any general-function DAN population would reveal itself as mediating consistent behavioral preference over all screens. However, none of the DAN subpopulations supported behavioral preferences to the extent our control neurons did; most did not support any preference at all, and those that did, supported only comparatively weak preferences (Fig. 3). In fact, the same DAN neurons can mediate both approach and avoidance depending either on variables of the experimental situation (e.g., line NP47) and even over time (Figs. 7, 8). Even the most consistent DAN driver lines did not stand up to re-screen scrutiny 
(Fig. 6), underscoring the comparatively fickle nature of DAN function in Drosophila operant activity. Whereas DAN function was reproducible within appropriately powered experiments (e.g., Fig. 7), none of the lines we screened appeared to be mediating the same valence consistently across several experimental setups (Fig. 4). At the same time, our control line stood out in its reproducibly aversive behavior (Fig. 3). The most straightforward explanation of this result is that, at least in flies, other neurons are involved in mediating operant control, either instead of or in addition to DANs and that DANs do not contribute to 'common currency' computations in flies.

However, the stark contrast between our control neurons (sensory neurons either for bitter taste or heat) reliably driving behavioral preferences and the fickle DANs may not necessarily be due to DANs not serving a role in 'common currency' calculations in flies. Alternatively, it is possible that our stimulation regime, which was optimized for our control neurons, may not be equally optimal for a set of non-sensory DANs. The stark difference in preference of the DAN lines in the two T-mazes, where the only difference is the wavelength of the optogenetic light, is consistent with this hypothesis. Stimulation-dependent value has also been observed in a two- 
choice optogenetic paradigm over long timescales driving activity in octopaminergic neurons (Claßen, 2018). If this were the case also for DANs, designing adequate control experiments is not straightforward and the design of a screen to search for such DANs would have to be dramatically different from the one we chose.

Currently there is no consensus on how to best stimulate DANs optogenetically. The usage varies from non-disclosed (König et al., 2019), to $10 \mathrm{~ms}$ at $50 \mathrm{~Hz}$ (McCurdy et al., 2021), to $250 \mathrm{~ms}$ pulse duration (Stern et al., 2019), to pulses of more than $1.2 \mathrm{~s}$ in duration and frequencies of 0.25Hz (König et al., 2018; Riemensperger et al., 2016). A systematic study found increasing amounts of dopamine released with increasing pulse width, frequency and duration when they varied these parameters from 1-4 ms and 10-60 $\mathrm{Hz}$ (Shin et al., 2020). Our regimes of $20 \mathrm{~Hz}$ stimulation with $10 \mathrm{~ms}$ (T-mazes) or $50 \mathrm{~ms}$ (Joystick) pulse-width do not seem to fall outside the range of what has been shown to be effective either behaviorally or in triggering dopamine release. Perhaps more worryingly, there may be an optimal stimulation protocol for any arbitrary set of any kind of neuron to drive approach or avoidance. In this case, any focus just on aminergic neurons may be unwarranted. 
Furthermore, the flies we tested were satiated. Appetitive DAN functions have always been found with starved or thirsty animals. It has been observed in other self-stimulation or self-administration experiments before that stronger preferences can be achieved when animals are starved (Carr, 2002; Fulton et al., 2004; Gnazzo et al., 2021). This explanation would only hold for appetitive DANs, aversive circuits ought not to be affected.

The possibility also remains that we did not test a line that would drive in the perfect combination of DANs to achieve a behavioral preference that is identical to or higher than that of our control lines. It is the main shortcoming of our work that only 13 of our nearly 50 DAN lines were tested in all four screens. However, even among the additional 12 DAN lines that were tested in three of the four screens, there were no strong candidates consistently performing at the extreme ends of all three screens (Fig. 3). Only line $\mathrm{TH}-\mathrm{C} 1$ performed consistently in all three screens it was tested in, but the score was close to zero in all cases. Of the 29 lines that were tested in two or more screens, no lines stood out as exceptionally consistent (Fig. 4). Therefore, we conclude that out of nearly 50 DAN subpopulations, there is no single line that can consistently mediate operant preference at the level of our control 
strains, strongly suggesting that DANs are not the only mediators involved in such operant behavior.

\section{Reinforcement is different from an unconditioned} stimulus

If there were no 'common currency' computation taking place in flies (or DANs were not part of it), one reason DAN function may vary between paradigms is that different neuronal mechanisms may be underlying performance in them. For instance, depending on experimental design, operant and classical experiments can be mediated by different biochemical pathways. Crucial for this distinction are not the general procedural differences between the two classes of experiments, but the content of the memory that is formed: classical experiments associate two events (i.e., CS and US) in the world around the subject (world-learning) and typically engage synaptic plasticity mediated by the cAMP pathway and phosphorylation by protein kinase $A$ (PKA)(Barbas et al., 2003; Giese and Mizuno, 2013; Lee, 2015; Matsumoto et al., 2018; Müller, 1999; Romano et al., 2006; Selcher et al., 2002; Wang and Peng, 2016; Wang and Zhang, 2012). In contrast, operant experiments that avoid contamination by environmental predictors (i.e., operant self-learning), depend on phosphorylation by 
protein kinase C (PKC)(Brembs and Plendl, 2008; Burguière et al., 2010; Colomb and Brembs, 2016; Lorenzetti et al., 2008; Rochefort et al., 2011; Watanabe et al., 2006, 2002; Yoshida et al., 2003) and the developmental activity of the transcription factor FoxP (Haesler et al., 2007; Lai et al., 2001; Mendoza et al., 2014; Norton et al., 2019; Scharff and Petri, 2011; Schreiweis et al., 2014).

The 'common currency' concept hinges on different situations converging on a common population of DANs. Perhaps this only appears as convergence because different DAN populations are treated as one population? It seems as if what used to be referred to as a homogenous "midbrain dopamine" population in mammals is much more heterogeneous than previously assumed (Anderegg et al., 2015; Cardoso and Lévesque, 2020; Hassan and Benarroch, 2015; Henny et al., 2012; Heymann et al., 2020; Lammel et al., 2014; Poulin et al., 2020). Specifically, dopaminergic function may differ between world-learning and self-learning components of the tasks in question, in particular via different dopaminergic projections to the striatum (Augustin et al., 2020; Da Cunha et al., 2012; Hassan and Benarroch, 2015; Heymann et al., 2020). With habit formation representing the experimental paradigm in mammals that mimics self-learning most closely (Brembs, 2009), the different roles ventromedial 
and ventrolateral striatum play in habit formation suggest differential roles of DAN circuits in worldand self-learning also in mammals. Given the small number of neurons in some of the lines we tested, it becomes conceivable that not all DAN populations that support classical conditioning need to also support operant preference in the same way. For instance, TH-D' neurons can substitute an aversive US in classical olfactory conditioning and also in our original screen, all four paradigms yielded negative scores for this line. In the Joystick rescreen, the initial reaction of the flies to activation of these neurons was also aversive - they switched the light off (Fig. 7). However, over time, continued operant control reduced the aversive properties of TH-D' activity (Fig. 8). The results emphasize that demonstrating a role of a set of neurons in processing a classical US is not sufficient to generalize from this instance to operant situations with reinforcement.

All animals process such re-afferent (operant) stimuli differently compared to ex-afferent (classical) stimuli. This is the reason we cannot tickle ourselves (Bays et al., 2006), why we perceive a stable visual world despite our frequent quick, or saccadic, eye movements (Sommer and Wurtz, 2006) and this differential processing is reflected in different brain activation patterns be- 
tween self-generated and exogenous visual stimulation (Matsuzawa et al., 2005). From this perspective, it may not be surprising that neurons found to encode a given value in classical (i.e., exafferent) situations do not necessarily have to sustain the matching preference in operant (i.e., re-afferent) situations: a classical US is not the same as reinforcement. This distinction can also be observed, e.g., when medial orbitofrontal cortex in rodents regulates operant avoidance but not Pavlovian fear (Ma et al., 2020).

An interesting case is the optogenetic activation of TH-Gal4 DANs in an operant olfactory conditioning paradigm in Drosophila (ClaridgeChang et al., 2009). In our screens, TH-Gal4 was tested in the T-mazes and the Joystick screen. In none of these screens did this line sustain substantial preference (Fig. 3). In contrast, (ClaridgeChang et al., 2009) showed that the activity in these neurons was sufficient to induce an aversive memory of the odor. Unfortunately, there is no data on the behavior of the flies during the training periods in this operant experiment, not even upon request, so it is impossible to tell if the flies avoided activation of the neurons or if the odor was conditioned as a classical side-effect of odor-activation pairings. This would not be the 
first time that such a dissociation between performance and learning would have been observed in flies (Kane et al., 1997).

A more recent optogenetic lever-pressing self-stimulation experiment in mice failed to find differences in dopamine release between classical and operant conditioning (Hollon et al., 2021). However, this study also failed to exclude all classical (world-learning) predictors from the experiment and, conversely, showed that the pressing behavior in question was irrelevant for the observed effect on dopamine release, as compared to the classical cue associated with the behavior, the depressed lever. Thus, the evidence from other preparations suggests that the effects the authors observed here are likely due to a contamination with classical cues that obscured any operant processes (Brembs and Plendl, 2008).

\section{Neuronal substrates of reinforcement}

DANs from the PAM cluster projecting to mushroom body substructures have long been considered to encode reward (Burke et al., 2012; Das et al., 2014; Lewis et al., 2015; Lin et al., 2014; Liu et al., 2012; McCurdy et al., 2021; Yamagata et al., 2015). One may ask, why none of these clusters seem to be relevant for operant activity as tested here. One explanation is that the previous results were gained from classical conditioning 
experiments with appropriately starved or waterdeprived animals, while our flies were satiated. Moreover, operant control has been shown to not require intact mushroom body function across a number of paradigms (Brembs, 2009; Brembs and Wiener, 2006; Putz and Heisenberg, 2002; Siwicki and Ladewski, 2003; Wolf et al., 1998), at least as long as odor processing is not involved. Hence, it may not be surprising that none of the DANs projecting to this neuropil supported consistent preferences in our screens (Fig. 3). As food or water are not the only rewards for flies, none of this should constitute an obstacle for identifying DANs encoding general reward. However, while we found DANs that mediated solid preference in each screen, we could not find any DANs that mediated consistent preference across all screens and held up in our rescreens.

Instead, the two most conspicuous lines, TH-D1 and TH-D', mainly comprise DANs from the PPL1 and PPM3 clusters, targeting central complex (CX) structures such as the fan-shaped body (FB) the ellipsoid body (EB) or the noduli, as well as the lateral accessory lobe (LAL; Fig. 5). The projection from the PPM3 cluster to the ventral FB (vFB) and noduli were particularly intense. vFB, which consists of layers 1 to 5 , is highly responsive to electric shock and nociceptive heat and mediates innate avoidance ( $\mathrm{Hu}$ et al., 2018), 
which may explain the (at least initial) avoidance behavior observed in both lines in our Joystick experiments (Figs. 6-8). However, this is not the only function of the FB. In addition to avoidance, the FB was reported to be important for locomotion control (Strauss, 2002), visual processing and pattern learning (Liu et al., 2006; Weir and Dickinson, 2015), or courtship maintenance (Sakai and Kitamoto, 2006). Dorsal components of the FB have been implied in sleep (Berry et al., 2015; Donlea et al., 2014, 2011; Qian et al., 2017; Ueno et al., 2012).

Together with the $\mathrm{FB}$, the EB and $\mathrm{LAL}$ are the most outstanding regions labelled by TH-D1 and TH-D' (Fig. 5). The EB encodes heading orientation and feature detection with the corresponding associated memories (Seelig and Jayaraman, 2015, 2013; Strauss, 2002; Wolff et al., 2015). Dop1R1 signaling in the EB ring neurons affect the temporal organization of motor actions, exploration and turning behavior (Kottler et al., 2019). Hence, the dopaminergic projections might reinforce different behaviors by biasing the action selection process in the ring neurons of the EB. Manipulating specific dopaminergic inputs into the ring neurons might show differential effects. The EB and the FB, as the other CX structures, protocerebral bridge and noduli, show a 
strikingly compartmentalized layout with restricted connections, which suggest a high degree of functional specialization (Kottler et al., 2019; Wolff et al., 2015; Wolff and Rubin, 2018). Hence, dopaminergic projections to the $C X$ and $L A L$ might be topographically organized to differentially drive avoidance and approach ( $\mathrm{Hu}$ et al., 2018; Wolff et al., 2015). The structure and function of the CX and LAL is quite conserved across insect's species. They process spatial aspects of complex multisensory information and integrate it with information about the insect's internal state and past experiences, to drive proper motor outputs (Buchanan et al., 2015; Hu et al., 2018; Namiki et al., 2018; Namiki and Kanzaki, 2018, 2016; Strauss, 2002; Wolff et al., 2015; Wolff and Rubin, 2018).

The LAL is the major output site of the CX and its bilaterally coordinated activity mediates signals to the thoracic motor centers. The $L A L$ is closely interconnected with other CX structures, but it also receives input from the anterior optic tract, superior medial protocerebrum, Lobula Plate, posterior slope and thoracic motor centers. In addition, the LAL receives ascending feedback about proprioceptive information to coordinate downstream motor commands in locomotion, flight, phonotaxis and pheromone orientation in several insects. The characteristic flip-flop signals 
observed in the LAL and downstream descending neurons are correlated with turning maneuvers and its role seems to be locomotion-biased, which points to this region as a major candidate where reinforcement might converge (Namiki et al., 2018; Namiki and Kanzaki, 2018, 2016; Wolff et al., 2015; Wolff and Rubin, 2018).

\section{Acknowledgments:}

We are grateful to our dedicated undergraduate students Gaia Bianchini, Avani Koparkar, Amanda Torres, Saurabh Bedi and Naman Agarwal, for their technical assistance in data collection during the initial screens. We are indebted to Hiromu Tanimoto for his generous sharing of fly stocks. Funding was provided by DFG grant BR 1892/16-1 to BB. None of this work would have been possible without the assistance of the electronics and precision mechanics workshops of the University of Regensburg.

\section{Author contributions:}

Study design and conceptualization $B B, C R$ and $B d B$. Data collection: $C R, B B, A K, K S$, FA, undergraduates. Data analysis: CR, BB. First draft: CR. Manuscript editing and commenting: all authors.

\section{References:}

Anderegg A, Poulin J-F, Awatramani R. 2015. Molecular heterogeneity of midbrain dopaminergic neurons--Moving toward single cell resolution. FEBS Lett 589:3714-3726.

Aso Y, Herb A, Ogueta M, Siwanowicz I, Templier T, Friedrich AB, Ito K, Scholz H, Tanimoto H. 2012. Three dopamine pathways induce aversive odor memories with different stability. PLoS Genet 8:e1002768.

Aso Y, Sitaraman D, Ichinose T, Kaun KR, Vogt K, Belliart-Guérin G, Plaçais P-Y, Robie AA, Yamagata N, Schnaitmann C, Rowell WJ, Johnston RM, Ngo T-TB, Chen N, Korff W, Nitabach MN, Heberlein U, Preat T, Branson KM, Tanimoto H, Rubin GM. 2014. Mushroom body output neurons encode valence and guide memory-based action selection in Drosophila. Elife 3:e04580. 
Aso Y, Siwanowicz I, Bräcker L, Ito K, Kitamoto T, Tanimoto H. 2010. Specific dopaminergic neurons for the formation of labile aversive memory. Curr Biol 20:1445-1451.

Augustin SM, Loewinger GC, O’Neal TJ, Kravitz AV, Lovinger DM. 2020. Dopamine D2 receptor signaling on iMSNs is required for initiation and vigor of learned actions. Neuropsychopharmacology 45:2087-2097.

Barbas D, DesGroseillers L, Castellucci VF, Carew TJ, Marinesco S. 2003. Multiple serotonergic mechanisms contributing to sensitization in aplysia: evidence of diverse serotonin receptor subtypes. Learn Mem 10:373-386.

Bayer HM, Glimcher PW. 2005. Midbrain dopamine neurons encode a quantitative reward prediction error signal. Neuron 47:129-141.

Bays PM, Flanagan JR, Wolpert DM. 2006. Attenuation of self-generated tactile sensations is predictive, not postdictive. PLoS Biol 4:e28.

Benjamin DJ, Berger JO, Johannesson M, Nosek BA, Wagenmakers E-J, Berk R, Bollen KA, Brembs B, Brown L, Camerer C, Cesarini D, Chambers CD, Clyde M, Cook TD, De Boeck P, Dienes Z, Dreber A, Easwaran K, Efferson C, Fehr E, Fidler F, Field AP, Forster M, George El, Gonzalez R, Goodman S, Green E, Green DP, Greenwald AG, Hadfield JD, Hedges LV, Held L, Hua Ho T, Hoijtink H, Hruschka DJ, Imai K, Imbens G, Ioannidis JPA, Jeon M, Jones JH, Kirchler M, Laibson D, List J, Little R, Lupia A, Machery E, Maxwell SE, McCarthy M, Moore DA, Morgan SL, Munafó M, Nakagawa S, Nyhan B, Parker TH, Pericchi L, Perugini M, Rouder J, Rousseau J, Savalei V, Schönbrodt FD, Sellke T, Sinclair B, Tingley D, Van Zandt T, Vazire S, Watts DJ, Winship C, Wolpert RL, Xie Y, Young C, Zinman J, Johnson VE. 2018. Redefine statistical significance. Nat Hum Behav 2:6-10.

Berridge KC, Kringelbach ML. 2015. Pleasure systems in the brain. Neuron 86:646-664.

Berry JA, Cervantes-Sandoval I, Chakraborty M, Davis RL. 2015. Sleep Facilitates Memory by Blocking Dopamine Neuron-Mediated Forgetting. Cell 161:1656-1667.

Brembs B. 2011. Spontaneous decisions and operant conditioning in fruit flies. Behav Processes 87:157-164.

Brembs B. 2009. Mushroom bodies regulate habit formation in Drosophila. Curr Biol 19:1351-1355.

Brembs B, Plendl W. 2008. Double dissociation of PKC and AC manipulations on operant and classical learning in Drosophila. Curr Biol 18:1168-1171.

Brembs B, Wiener J. 2006. Context and occasion setting in Drosophila visual learning. Learn Mem 13:618-628.

Buchanan SM, Kain JS, de Bivort BL. 2015. Neuronal control of locomotor handedness in Drosophila. Proc Natl Acad Sci U S A 112:6700-6705.

Burguière E, Arabo A, Jarlier F, De Zeeuw Cl, Rondi-Reig L. 2010. Role of the cerebellar cortex in conditioned goal-directed behavior. J Neurosci 30:13265-13271. 
Burke CJ, Huetteroth W, Owald D, Perisse E, Krashes MJ, Das G, Gohl D, Silies M, Certel S, Waddell S. 2012. Layered reward signalling through octopamine and dopamine in Drosophila. Nature 492:433-437.

Cardoso T, Lévesque M. 2020. Toward Generating Subtype-Specific Mesencephalic Dopaminergic Neurons. Front Cell Dev Biol 8:443.

Carr KD. 2002. Augmentation of drug reward by chronic food restriction: behavioral evidence and underlying mechanisms. Physiol Behav 76:353-364.

Claridge-Chang A, Roorda RD, Vrontou E, Sjulson L, Li H, Hirsh J, Miesenböck G. 2009. Writing memories with light-addressable reinforcement circuitry. Cell 139:405-415.

Claßen GR. 2018. The Role of Octopamine in Attraction and Aversion Behavior in Drosophila melanogaster (text.thesis.doctoral). Universität zu Köln.

Colomb J, Brembs B. 2016. PKC in motorneurons underlies self-learning, a form of motor learning in Drosophila. PeerJ 4:e1971.

Colomb J, Brembs B. 2010. The biology of psychology: "Simple" conditioning? Commun Integr Biol 3:142-145.

Da Cunha C, Gomez-A A, Blaha CD. 2012. The role of the basal ganglia in motivated behavior. Rev Neurosci 23:747-767.

Das G, Klappenbach M, Vrontou E, Perisse E, Clark CM, Burke CJ, Waddell S. 2014. Drosophila learn opposing components of a compound food stimulus. Curr Bio/ 24:1723-1730.

Donlea JM, Pimentel D, Miesenböck G. 2014. Neuronal machinery of sleep homeostasis in Drosophila. Neuron 81:860-872.

Donlea JM, Thimgan MS, Suzuki Y, Gottschalk L, Shaw PJ. 2011. Inducing sleep by remote control facilitates memory consolidation in Drosophila. Science 332:1571-1576.

Fulton S, Richard D, Woodside B, Shizgal P. 2004. Food restriction and leptin impact brain reward circuitry in lean and obese Zucker rats. Behav Brain Res 155:319-329.

Galili DS. 2014. Neural circuits mediating aversive olfactory conditioning in Drosophila. Ludwig-Maximilians-Universität München. doi:10.5282/EDOC.17542

Giese KP, Mizuno K. 2013. The roles of protein kinases in learning and memory. Learn Mem 20:540-552.

Gnazzo FG, Mourra D, Guevara CA, Beeler JA. 2021. Chronic food restriction enhances dopamine-mediated intracranial self-stimulation. Neuroreport. doi:10.1097/WNR.0000000000001700

Gorostiza EA, Colomb J, Brembs B. 2016. A decision underlies phototaxis in an insect. Open Bio/ 6. doi:10.1098/rsob.160229

Grabenhorst F, Rolls ET. 2011. Value, pleasure and choice in the ventral prefrontal cortex. Trends Cogn Sci 15:56-67. 
Guo A, Li L, Xia SZ, Feng CH, Wolf R, Heisenberg M. 1996. Conditioned visual flight orientation in Drosophila: dependence on age, practice, and diet. Learn Mem 3:49-59.

Haesler S, Rochefort C, Georgi B, Licznerski P, Osten P, Scharff C. 2007. Incomplete and inaccurate vocal imitation after knockdown of FoxP2 in songbird basal ganglia nucleus Area X. PLOS Biol 5:e321.

Hassan A, Benarroch EE. 2015. Heterogeneity of the midbrain dopamine system: Implications for Parkinson disease. Neurology 85:1795-1805.

Henny P, Brown MTC, Northrop A, Faunes M, Ungless MA, Magill PJ, Bolam JP. 2012. Structural correlates of heterogeneous in vivo activity of midbrain dopaminergic neurons. Nat Neurosci 15:613-619.

Heymann G, Jo YS, Reichard KL, McFarland N, Chavkin C, Palmiter RD, Soden ME, Zweifel LS. 2020. Synergy of Distinct Dopamine Projection Populations in Behavioral Reinforcement. Neuron 105:909-920.e5.

Hollon NG, Williams EW, Howard CD, Li H, Traut TI, Jin X. 2021. Nigrostriatal dopamine signals sequence-specific action-outcome prediction errors. Curr Biol. doi:10.1016/j.cub.2021.09.040

Hu W, Peng Y, Sun J, Zhang F, Zhang X, Wang L, Li Q, Zhong Y. 2018. Fan-Shaped Body Neurons in the Drosophila Brain Regulate Both Innate and Conditioned Nociceptive Avoidance. Cell Rep 24:1573-1584.

Kane NS, Robichon A, Dickinson JA, Greenspan RJ. 1997. Learning without performance in PKC-deficient Drosophila. Neuron 18:307-314.

Kim Y-C, Lee H-G, Han K-A. 2007. D1 dopamine receptor dDA1 is required in the mushroom body neurons for aversive and appetitive learning in Drosophila. J Neurosci 27:76407647.

Klapoetke NC, Murata Y, Kim SS, Pulver SR, Birdsey-Benson A, Cho YK, Morimoto TK, Chuong AS, Carpenter EJ, Tian Z, Wang J, Xie Y, Yan Z, Zhang Y, Chow BY, Surek B, Melkonian M, Jayaraman V, Constantine-Paton M, Wong GK-S, Boyden ES. 2014. Independent optical excitation of distinct neural populations. Nat Methods 11:338-346.

Kobayashi K, Hsu M. 2019. Common neural code for reward and information value. Proc Natl Acad Sci U S A 116:13061-13066.

König C, Khalili A, Ganesan M, Nishu AP, Garza AP, Niewalda T, Gerber B, Aso Y, Yarali A. 2018. Reinforcement signaling of punishment versus relief in fruit flies. Learn Mem 25:247257.

König C, Khalili A, Niewalda T, Gao S, Gerber B. 2019. An optogenetic analogue of secondorder reinforcement in Drosophila. Biol Lett 15:20190084.

Kottler B, Faville R, Bridi JC, Hirth F. 2019. Inverse Control of Turning Behavior by Dopamine D1 Receptor Signaling in Columnar and Ring Neurons of the Central Complex in Drosophila. Curr Bio/ 29:567-577.e6. 
Kremer Y, Flakowski J, Rohner C, Lüscher C. 2020. Context-Dependent Multiplexing by Individual VTA Dopamine Neurons. J Neurosci 40:7489-7509.

Lai CS, Fisher SE, Hurst JA, Vargha-Khadem F, Monaco AP. 2001. A forkhead-domain gene is mutated in a severe speech and language disorder. Nature 413:519-523.

Lak A, Stauffer WR, Schultz W. 2014. Dopamine prediction error responses integrate subjective value from different reward dimensions. Proc Natl Acad Sci U S A 111:2343-2348.

Lakens D, Adolfi FG, Albers CJ, Anvari F, Apps MAJ, Argamon SE, Baguley T, Becker RB, Benning SD, Bradford DE, Buchanan EM, Caldwell AR, Van Calster B, Carlsson R, Chen S-C, Chung B, Colling LJ, Collins GS, Crook Z, Cross ES, Daniels S, Danielsson H, DeBruine L, Dunleavy DJ, Earp BD, Feist MI, Ferrell JD, Field JG, Fox NW, Friesen A, Gomes C, GonzalezMarquez M, Grange JA, Grieve AP, Guggenberger R, Grist J, van Harmelen A-L, Hasselman F, Hochard KD, Hoffarth MR, Holmes NP, Ingre M, Isager PM, Isotalus HK, Johansson C, Juszczyk K, Kenny DA, Khalil AA, Konat B, Lao J, Larsen EG, Lodder GMA, Lukavský J, Madan CR, Manheim D, Martin SR, Martin AE, Mayo DG, McCarthy RJ, McConway K, McFarland C, Nio AQX, Nilsonne G, de Oliveira CL, de Xivry J-JO, Parsons S, Pfuhl G, Quinn KA, Sakon JJ, Saribay SA, Schneider IK, Selvaraju M, Sjoerds Z, Smith SG, Smits T, Spies JR, Sreekumar V, Steltenpohl CN, Stenhouse N, Świątkowski W, Vadillo MA, Van Assen MALM, Williams MN, Williams SE, Williams DR, Yarkoni T, Ziano I, Zwaan RA. 2018. Justify your alpha. Nat Hum Behav 2:168-171.

Lammel S, Lim BK, Malenka RC. 2014. Reward and aversion in a heterogeneous midbrain dopamine system. Neuropharmacology 76 Pt B:351-359.

Landreth A, Bickle J. 2008. Neuroeconomics, neurophysiology and the common currency hypothesis. Econ Philos 24:419-429.

Lee D. 2015. Global and local missions of cAMP signaling in neural plasticity, learning, and memory. Front Pharmaco/ 6:161.

Lesar A, Tahir J, Wolk J, Gershow M. 2021. Switch-like and persistent memory formation in individual. Elife 10. doi:10.7554/eLife.70317

Levy DJ, Glimcher PW. 2012. The root of all value: a neural common currency for choice. Curr Opin Neurobiol 22:1027-1038.

Lewis LPC, Siju KP, Aso Y, Friedrich AB, Bulteel AJB, Rubin GM, Grunwald Kadow IC. 2015. A Higher Brain Circuit for Immediate Integration of Conflicting Sensory Information in Drosophila. Curr Biol 25:2203-2214.

Lin S, Owald D, Chandra V, Talbot C, Huetteroth W, Waddell S. 2014. Neural correlates of water reward in thirsty Drosophila. Nat Neurosci 17:1536-1542.

Liu C, Plaçais P-Y, Yamagata N, Pfeiffer BD, Aso Y, Friedrich AB, Siwanowicz I, Rubin GM, Preat T, Tanimoto H. 2012. A subset of dopamine neurons signals reward for odour memory in Drosophila. Nature 488:512-516. 
Liu G, Seiler H, Wen A, Zars T, Ito K, Wolf R, Heisenberg M, Liu L. 2006. Distinct memory traces for two visual features in the Drosophila brain. Nature 439:551-556.

Lorenzetti FD, Baxter DA, Byrne JH. 2008. Molecular mechanisms underlying a cellular analog of operant reward learning. Neuron 59:815-828.

Ma C, Jean-Richard-Dit-Bressel P, Roughley S, Vissel B, Balleine BW, Killcross S, Bradfield LA. 2020. Medial Orbitofrontal Cortex Regulates Instrumental Conditioned Punishment, but not Pavlovian Conditioned Fear. Cereb Cortex Commun 1:tgaa039.

Marella S, Fischler W, Kong P, Asgarian S, Rueckert E, Scott K. 2006. Imaging taste responses in the fly brain reveals a functional map of taste category and behavior. Neuron 49:285295.

Matsumoto H, Tian J, Uchida N, Watabe-Uchida M. 2016. Midbrain dopamine neurons signal aversion in a reward-context-dependent manner. Elife 5. doi:10.7554/eLife.17328

Matsumoto Y, Matsumoto CS, Mizunami M. 2018. Signaling Pathways for Long-Term Memory Formation in the Cricket. Front Psychol 9:1014.

Matsuzawa M, Matsuo K, Sugio T, Kato C, Nakai T. 2005. Temporal relationship between action and visual outcome modulates brain activation: an fMRI study. Magn Reson Med Sci 4:115-121.

McCurdy LY, Sareen P, Davoudian PA, Nitabach MN. 2021. Dopaminergic mechanism underlying reward-encoding of punishment omission during reversal learning in Drosophila. Nat Commun 12:1115.

Mendoza E, Colomb J, Rybak J, Pflüger H-J, Zars T, Scharff C, Brembs B. 2014. Drosophila FoxP mutants are deficient in operant self-learning. PLoS One 9:e100648.

Müller U. 1999. Second messenger pathways in the honeybee brain: immunohistochemistry of protein kinase A and protein kinase C. Microsc Res Tech 45:165-173.

Namiki S, Dickinson MH, Wong AM, Korff W, Card GM. 2018. The functional organization of descending sensory-motor pathways in Drosophila. Elife 7. doi:10.7554/elife.34272

Namiki S, Kanzaki R. 2018. Morphology of visual projection neurons supplying premotor area in the brain of the silkmoth Bombyx mori. Cell Tissue Res 374:497-515.

Namiki S, Kanzaki R. 2016. Comparative Neuroanatomy of the Lateral Accessory Lobe in the Insect Brain. Front Physiol 7:244.

Norton P, Barschke P, Scharff C, Mendoza E. 2019. Differential Song Deficits after LentivirusMediated Knockdown of FoxP1, FoxP2, or FoxP4 in Area X of Juvenile Zebra Finches. $J$ Neurosci 39:9782-9796.

Pathak T, Agrawal T, Richhariya S, Sadaf S, Hasan G. 2015. Store-Operated Calcium Entry through Orai Is Required for Transcriptional Maturation of the Flight Circuit in Drosophila. J Neurosci 35:13784-13799. 
Poulin J-F, Gaertner Z, Moreno-Ramos OA, Awatramani R. 2020. Classification of Midbrain Dopamine Neurons Using Single-Cell Gene Expression Profiling Approaches. Trends Neurosci 43:155-169.

Putz G, Heisenberg M. 2002. Memories in drosophila heat-box learning. Learn Mem 9:349359.

Qian Y, Cao Y, Deng B, Yang G, Li J, Xu R, Zhang D, Huang J, Rao Y. 2017. Sleep homeostasis regulated by $5 \mathrm{HT} 2 \mathrm{~b}$ receptor in a small subset of neurons in the dorsal fan-shaped body of drosophila. Elife 6. doi:10.7554/eLife.26519

Qin H, Cressy M, Li W, Coravos JS, Izzi SA, Dubnau J. 2012. Gamma neurons mediate dopaminergic input during aversive olfactory memory formation in Drosophila. Curr Biol 22:608-614.

Riemensperger T, Kittel RJ, Fiala A. 2016. Optogenetics in Drosophila Neuroscience. Methods Mol Biol 1408:167-175.

Rochefort C, Arabo A, André M, Poucet B, Save E, Rondi-Reig L. 2011. Cerebellum shapes hippocampal spatial code. Science 334:385-389.

Rohrsen C. 2019. The neuronal substrates of reinforcement and punishment in Drosophila melanogaster. doi:10.5283/EPUB.40740

Rohwedder A, Wenz NL, Stehle B, Huser A, Yamagata N, Zlatic M, Truman JW, Tanimoto H, Saumweber T, Gerber B, Thum AS. 2016. Four Individually Identified Paired Dopamine Neurons Signal Reward in Larval Drosophila. Curr Biol 26:661-669.

Romano A, Locatelli F, Freudenthal R, Merlo E, Feld M, Ariel P, Lemos D, Federman N, Fustiñana MS. 2006. Lessons from a crab: molecular mechanisms in different memory phases of Chasmagnathus. Biol Bull 210:280-288.

Sakai T, Kitamoto T. 2006. Differential roles of two major brain structures, mushroom bodies and central complex, for Drosophila male courtship behavior. J Neurobio/ 66:821-834.

Scharff C, Petri J. 2011. Evo-devo, deep homology and FoxP2: implications for the evolution of speech and language. Philos Trans R Soc Lond B Biol Sci 366:2124-2140.

Schleyer M, Diegelmann S, Michels B, Saumweber T, Gerber B. 2013. Invertebrate Learning and Memory: Chapter 5. "Decision Making" in Larval Drosophila. Elsevier Inc. Chapters.

Schleyer M, Weiglein A, Thoener J, Strauch M, Hartenstein V, Kantar Weigelt M, Schuller S, Saumweber T, Eichler K, Rohwedder A, Merhof D, Zlatic M, Thum AS, Gerber B. 2020. Identification of Dopaminergic Neurons That Can Both Establish Associative Memory and Acutely Terminate Its Behavioral Expression. J Neurosci 40:5990-6006.

Schreiweis C, Bornschein U, Burguière E, Kerimoglu C, Schreiter S, Dannemann M, Goyal S, Rea E, French CA, Puliyadi R, Groszer M, Fisher SE, Mundry R, Winter C, Hevers W, Pääbo S, Enard W, Graybiel AM. 2014. Humanized Foxp2 accelerates learning by enhancing transitions from declarative to procedural performance. Proc Natl Acad Sci U S A 111:14253-14258. 
Schultz W. 2019. Recent advances in understanding the role of phasic dopamine activity. F1000Res 8. doi:10.12688/f1000research.19793.1

Schultz W. 2017. Reward prediction error. Curr Bio/ 27:R369-R371.

Schultz W. 2016. Dopamine reward prediction-error signalling: a two-component response. Nat Rev Neurosci 17:183-195.

Schultz W, Apicella P, Ljungberg T. 1993. Responses of monkey dopamine neurons to reward and conditioned stimuli during successive steps of learning a delayed response task. J Neurosci 13:900-913.

Schultz W, Carelli RM, Wightman RM. 2015. Phasic dopamine signals: from subjective reward value to formal economic utility. Curr Opin Behav Sci 5:147-154.

Schwaerzel M, Monastirioti M, Scholz H, Friggi-Grelin F, Birman S, Heisenberg M. 2003. Dopamine and octopamine differentiate between aversive and appetitive olfactory memories in Drosophila. J Neurosci 23:10495-10502.

Seelig JD, Jayaraman V. 2015. Neural dynamics for landmark orientation and angular path integration. Nature 521:186-191.

Seelig JD, Jayaraman V. 2013. Feature detection and orientation tuning in the Drosophila central complex. Nature 503:262-266.

Selcher JC, Weeber EJ, Varga AW, Sweatt JD, Swank M. 2002. Protein kinase signal transduction cascades in mammalian associative conditioning. Neuroscientist 8:122-131.

Shin M, Copeland JM, Venton BJ. 2020. Real-Time Measurement of Stimulated Dopamine Release in Compartments of the Adult Mushroom Body. Anal Chem 92:14398-14407.

Siwicki KK, Ladewski L. 2003. Associative learning and memory in Drosophila: beyond olfactory conditioning. Behav Processes 64:225-238.

Sommer MA, Wurtz RH. 2006. Influence of the thalamus on spatial visual processing in frontal cortex. Nature 444:374-377.

Stern U, Srivastava H, Chen H-L, Mohammad F, Claridge-Chang A, Yang C-H. 2019. Learning a Spatial Task by Trial and Error in Drosophila. Curr Biol 29:2517-2525.e5.

Strauss R. 2002. The central complex and the genetic dissection of locomotor behaviour. Curr Opin Neurobiol 12:633-638.

Tempel BL, Livingstone MS, Quinn WG. 1984. Mutations in the dopa decarboxylase gene affect learning in Drosophila. Proc Natl Acad Sci U S A 81:3577-3581.

Ueno T, Tomita J, Tanimoto H, Endo K, Ito K, Kume S, Kume K. 2012. Identification of a dopamine pathway that regulates sleep and arousal in Drosophila. Nat Neurosci 15:15161523.

Wang H, Peng R-Y. 2016. Basic roles of key molecules connected with NMDAR signaling pathway on regulating learning and memory and synaptic plasticity. Mil Med Res 3:26. 
Wang H, Zhang M. 2012. The role of $\mathrm{Ca}^{2+}$-stimulated adenylyl cyclases in bidirectional synaptic plasticity and brain function. Rev Neurosci 23:67-78.

Watanabe A, Kimura T, Sakaguchi H. 2002. Expression of protein kinase $\mathrm{C}$ in song control nuclei of deafened adult male Bengalese finches. Neuroreport 13:127-132.

Watanabe A, Li R, Kimura T, Sakaguchi H. 2006. Lesions of an avian forebrain nucleus prevent changes in protein kinase $C$ levels associated with deafening-induced vocal plasticity in adult songbirds. Eur J Neurosci 23:2447-2457.

Weir PT, Dickinson MH. 2015. Functional divisions for visual processing in the central brain of flying Drosophila. Proc Natl Acad Sci U S A 112:E5523-32.

Werkhoven Z, Rohrsen C, Qin C, Brembs B, de Bivort B. 2019. MARGO (Massively Automated Real-time GUI for Object-tracking), a platform for high-throughput ethology. PLoS One 14:e0224243.

White KE, Humphrey DM, Hirth F. 2010. The dopaminergic system in the aging brain of Drosophila. Front Neurosci 4:205.

Wolff T, lyer NA, Rubin GM. 2015. Neuroarchitecture and neuroanatomy of the Drosophila central complex: A GAL4-based dissection of protocerebral bridge neurons and circuits. J Comp Neurol 523:997-1037.

Wolff T, Rubin GM. 2018. Neuroarchitecture of the Drosophila central complex: A catalog of nodulus and asymmetrical body neurons and a revision of the protocerebral bridge catalog. J Comp Neurol 526:2585-2611.

Wolf R, Wittig T, Liu L, Wustmann G, Eyding D, Heisenberg M. 1998. Drosophila mushroom bodies are dispensable for visual, tactile, and motor learning. Learn Mem 5:166-178.

Yamagata N, Ichinose T, Aso Y, Plaçais P-Y, Friedrich AB, Sima RJ, Preat T, Rubin GM, Tanimoto H. 2015. Distinct dopamine neurons mediate reward signals for short- and long-term memories. Proc Natl Acad Sci U S A 112:578-583.

Yoshida Y, Yamada T, Sakaguchi H. 2003. Activation of protein kinase $C$ by the error signal from a basal ganglia-forebrain circuit in the zebra finch song control nuclei. Neuroreport 14:645-649. 